\title{
Overcoming students' misconceptions concerning thermal physics with the aid of hints and peer interaction during a lecture course
}

\author{
Risto Leinonen, ${ }^{*}$ Mervi A. Asikainen, and Pekka E. Hirvonen \\ Department of Physics and Mathematics, University of Eastern Finland, Yliopistokatu 7, 80100 Joensuu, Finland
}

(Received 9 November 2012; published 12 September 2013)

\begin{abstract}
As has been shown by previous research, students may possess various misconceptions in the area of thermal physics. In order to help them overcome misconceptions observed prior to instruction, we implemented a one-hour lecture-based intervention in their introductory thermal physics course. The intervention was held after the conventional lectures and homework sessions, and it consisted of three phases: individual working, hinting, and peer discussion. To probe students' conceptual understanding before, during, and after the intervention, use was made of a diagnostic test related to the multiphased process of an ideal gas [D.E. Meltzer, Am. J. Phys. 72, 1432 (2004)]. The students' conceptions were monitored by analyzing the explanations they provided and by recording the peer discussions of five voluntary pairs. The intervention helped students to realize the flaws in their explanations and increased the proportion of their scientific explanations, the increase being statistically significant in five tasks out of seven. When the same themes were addressed in a post-test, it was shown that the level of accurate explanations remained almost constant after the intervention, and hence it could be deduced that the impact had not been short-lived. In comparison with earlier studies conducted with the same material, our intervention produced a better learning outcome, the difference being 15-20 percentage points. In addition, the number of misconceptions on the part of the students was smaller in our study, although with individual exceptions. Hence, we conclude that the intervention was successful and that similar interventions could also be designed and implemented in other areas of physics.
\end{abstract}

DOI: 10.1103/PhysRevSTPER.9.020112

PACS numbers: 01.40.gb, 51.30.+i, 05.70.Ce

\section{INTRODUCTION}

Thermal physics possesses a rich network of concepts, including many that overlap to varying degrees with respect to a variety of aspects. For example, defining heat as "energy in transit from one body to another as a result of a temperature difference" [1] links heat with two new concepts: energy and temperature. Defining energy leads to a discussion of microscopic models that will, in turn, link temperature with the kinetic energy of particles. For many students, this kind of structure with its numerous interrelations is challenging. In addition, terms that are familiar from everyday life have a different meaning in physics, which can further confuse students [2,3]. Thus, it seems evident that university students face a large number of problems in learning about thermal physics.

A great amount of work has already been done with regard to research into the teaching and learning of thermal physics at university. The numerous misconceptions and problems found have served as starting points for designing teaching interventions aimed at improving students' learning outcomes [4-7]. The results indicate that

\footnotetext{
*risto.leinonen@uef.fi
}

Published by the American Physical Society under the terms of the Creative Commons Attribution 3.0 License. Further distribution of this work must maintain attribution to the author(s) and the published article's title, journal citation, and DOI. conceptual understanding undergoes improvement when the active participation of the students themselves is emphasized [5-7]. However, most of these interventions require special training, extra resources, and possibly also curriculum reformulations, all of which may restrict their use in typical institutions. As a consequence, we formulated a research-based teaching intervention that could be implemented in an ordinary lecture setting and with no special training or resources.

The aim of our research is to improve students' conceptual understanding by implementing an intervention at an introductory level that makes use of hints and peer interaction in thermal physics. In this research, change in students' conceptual understanding is examined by monitoring students' misconceptions and the ways in which they sought to overcome them. Our research question is formulated as follows:

How do hinting and peer-interaction help university students to overcome well-known misconceptions concerning thermal physics at an introductory level?

When discussing misconceptions, we refer to ideas that conflict with accepted scientific ideas [8,9]. We acknowledge the negative nuances associated with the term, but we decided to use this particular term because of its general usage and familiarity [10]. Hammer describes the term misconception in terms of the following four properties: 
(1) it is strongly held and stable, (2) it differs from expert conceptions, (3) it affects students' understanding of natural phenomena and scientific explanations, and (4) it has to be overcome so that a scientific view can be reached [10]. We base our use of the concept on this description, as specified in the following section. ${ }^{1}$

The first property is not treated as if misconceptions were necessarily unambiguous or clearly defined. They can also be adaptable, depending on context, and students may possess and use various misconceptions in parallel. In our usage, this property is regarded from the perception that a student tends to rely on a specific misconception, and these ideas are somewhat stable and often rather resistant to related teaching. The second property, in our usage, means that all students' ideas differing from a desired scientific conception can be labeled misconceptions. This refers variously to misunderstanding how concepts are related to each other, misunderstanding the scientific meanings of concepts, and applying the principles of physics imperfectly, to name only a few of the possibilities. The third property is closely connected to the previous one. Inaccurate ideas affect students' understanding and interpretations of phenomena. Misconceptions may produce partly accurate predictions vis-à-vis some phenomena, but their explanatory power is more limited than that of scientific conceptions. The fourth property concentrates on the way to locate a scientific view. In our usage, this means that students' misconceptions have to be overcome and substituted with ideas that have greater explanatory power, namely, scientific conceptions. This can be a relatively complicated cognitive process, and there may even exist so-called intermediate conceptions between misconceptions and scientific conceptions, which can be seen as "stepping stones" toward desirable learning. In our usage, misconceptions are evaluated as relatively concrete entities that can be substituted by other conceptions when students acknowledge their existence. In the present study, we focus on the ways in which misconceptions can be overcome.

Misunderstanding the meanings of concepts is one example of the kind of misconceptions harbored by students. The link between pressure and mechanical equilibrium [6] seems to be a problem, as is the connection between temperature and thermal equilibrium [11]. There also exists a tendency to assume that changes in pressure are related to changes in density, and similarly that changes in temperature are related to changes in particle density $[7,12]$. In addition, microscopic models seem to be challenging since temperature and pressure are often understood as being opposed to each other [7,13].

The issue that has probably received the greatest attention is students' ability to distinguish between heat

\footnotetext{
${ }^{1}$ This set of properties is regarded among some scientists as somewhat controversial, but our usage of the concept follows Hammer's ideas closely.
}

and temperature $[5,6,14,15]$. It has also been shown that heat may be confused with enthalpy, internal energy, and also work $[6,14,16,17]$. Confusions of this kind can also be found in textbooks where language is used imprecisely [18].

Problems concerned with the essential concepts of heat and work are not limited to linguistic ones. Students also experience problems in understanding their meanings. One crucial finding is students' tendency to consider these to be state quantities $[3,6,16,17]$ or to be independent of process, including the idea that work and heat equal zero in a cyclic process [17]. Furthermore, problems with signs of work and heat seem to be relatively common among students $[16,19,20]$. It should also be acknowledged that students frequently produce erroneous microscopic explanations. They often tend to think, for example, that colliding particles produce heat or kinetic energy $[7,12,17]$.

Despite the apparent simplicity of the first law of thermodynamics related to heat and work [3], numerous learning problems have been observed. Students seem not to understand the importance of the law, or they tend to use other, conflicting explanations such as the ideal gas law, instead $[5,6,16,21]$. The impact of work on the internal energy of a system is often ignored [17], or it is claimed that the energy of the system always stays constant [2]. In addition, students may not understand the relevance of $p V$ diagrams as a problem-solving tool when determining work in various processes [17].

A review of the literature related to the gas laws and thermal processes provides further insight into students' problems. An essential finding related to the ideal gas model is students' tendency to concentrate on the dependencies between two quantities by ignoring a third quantity completely $[6,12,21]$. Moreover, students tend to confuse processes by claiming that temperature will remain constant in an adiabatic process and heat will equal zero in an isothermal process $[6,13,16]$.

\section{INTERVENTION}

In order to strengthen our students' conceptual understanding and to help them overcome the misconceptions left after lectures and homework sessions, we implemented a teaching intervention in an introductory course dealing with thermal physics. The following section therefore describes the course and the construction and implementation of the intervention.

\section{A. Course}

An intervention was implemented and data were collected in the Basic Physics II introductory course at the University of Eastern Finland, Department of Physics and Mathematics. The course forms part of the basic studies in physics that consists of four lecture courses and one laboratory course designed for both physics majors and physics minors. A typical lecture course consists of 32-40 class periods (45 min) of lectures and 16-20 class periods of 
TABLE I. Time allocation in relation to the thermal physics content in the Basic Physics II course [22].

\begin{tabular}{|c|c|c|}
\hline Chapter & Content & $\begin{array}{c}\text { Time usage } \\
\text { (45 min class periods) } \\
\text { lectures }+ \text { homework } \\
\text { sessions }\end{array}$ \\
\hline 16. Macroscopic description of matter & $\begin{array}{l}\text { States of matter, atoms and moles, temperature, phase changes, } \\
\text { ideal gas model, law, and processes }\end{array}$ & $4+2$ \\
\hline $\begin{array}{l}\text { 17. Work, heat, and the first law of } \\
\text { thermodynamics }\end{array}$ & $\begin{array}{l}\text { Energy, work, heat, the first law, properties of matter, } \\
\text { calorimetry, heat transfer mechanisms }\end{array}$ & $6+2$ \\
\hline 18. The micro-to-macro connection & $\begin{array}{l}\text { Molecular speeds and collisions, pressure in a gas, temperature, } \\
\text { thermal energy and specific heat }\end{array}$ & $3+2$ \\
\hline
\end{tabular}

homework sessions, related to ECTS $^{2}$ credits, in these particular cases 4 or 5 credits. During the laboratory course, students perform and report on 10 laboratory experiments related to topics covered in their lecture courses. The totality of the basic studies in physics is based on material by Knight [22]. The basics of kinematics, mechanics, thermal physics, waves and optics, electricity, magnetism, and quantum physics are introduced in the course of the studies.

The Basic Physics II course has 100-120 participants. The course itself is based on the textbook by Knight, but it also includes other supplementary materials [22-24]. As a complete unit, the course consisted of 32 class periods of lectures, 16 class periods of homework sessions, and a course exam. In the course of a single week, 6 class periods of lectures, and 2 class periods of homework sessions were implemented, homework sessions following one week behind the lectures. The thermal physics content took up 13 class periods of lectures and 6 class periods of homework sessions. A summary of the contents of the thermal physics part of the course and the time allocated to lectures and homework sessions can be seen in Table I.

The language of teaching was Finnish. A majority of the students had English textbooks [22], but the lecture material, homework tasks, and intervention materials were prepared in Finnish. In homework sessions, students introduced their solutions to the exercises that had been distributed beforehand, and a teaching assistant corrected and commented on them when needed. The course included no laboratory exercises. Participation in the lectures and homework sessions was voluntary, but students were rewarded with a few extra points, a maximum of $10 \%$ of the course grade, based on the number of homework exercises completed. In practice, more than half of the students participated in the lectures and homework sessions. At the end of the course, a course exam was held. The course grade was determined by points from this exam

\footnotetext{
${ }^{2}$ ECTS stands for the European Credit Transfer and Accumulation System. This is the standard used for study credits in the European Union and several other European countries. One ECTS credit corresponds to 25-30 hours of work.
}

supplemented with the possible extra points mentioned earlier.

The teaching offered in the lectures was organized in the main by following the ideas put forward by Knight. In practice, conventional lectures were supplemented with conceptual questions adapted from various books by Knight [22-24]. Small modifications were made to the questions, such as adding multiple-choice items. After working individually, students were asked to compare and discuss their answers with their peers. An overview of students' answers was obtained by asking them to raise their hands after both phases. When the correct answer was revealed, students had worked actively by themselves, so grasping the properly explained correct answer provided by the instructor should be easier. This kind of teaching has similarities to peer instruction (PI) [25], which is briefly introduced in the instructor guide [24]. This kind of segment was repeated a few times during the lectures, always following the same format.

\section{B. Constructing the intervention}

After the lectures and the subsequent homework sessions, the intervention, which was labeled as HPIL teaching (hints and peer interaction in lectures), was implemented. The intervention utilized Meltzer's diagnostic test ${ }^{3}$ related to the multiphase process of an ideal gas [17]. In order to succeed in the test, a student should be familiar with the first law of thermodynamics, thermal processes, and the interdependencies of certain quantities; all of these had been crucial topics covered prior to the intervention.

The idea behind the intervention was to help students to use the familiar content by utilizing scaffolding.

\footnotetext{
${ }^{3}$ Minor changes regarding wording and numbering were made so that the test better suited our purposes. The largest change was made to question 6 regarding the work of a cyclic process; we inquired about work done on the gas rather than work done by the gas. The reason for this was that the first law of thermodynamics is presented in a different form in the courses taught $[17,22]$. We also excluded two final questions that addressed the same themes in a slightly different situation. The test was originally used as a basis for interviews, but it has also been used as a diagnostic test [26,27].
} 
Scaffolding refers to a process where a learner is helped to succeed in an otherwise unachievable task with appropriate assistance [28]. Originally, the term referred to processes in which the help was offered by an instructor [29]. Nowadays, the concept covers help offered to a larger cohort than simply an individual learner [30], and also includes help offered by peers [31]. In this study, scaffolding was implemented by providing the whole cohort with hints about the physics content and by giving them an opportunity to discuss topics with their peers.

The hints that were given were based on earlier research findings. They were designed so that each hint addressed a specific misconception. The hints did not provide any information that is outside the course content, so the role that they played was primarily in helping students to use content matter that had already been taught, rather than teaching new content. Details of the hints are presented in Appendix A.

The implementation of discussions between two students as the final part of our intervention was intended to help students to examine both their own content knowledge and also that of their peers. Like the hinting phase, this activity ought to help students in overcoming their possible misconceptions and in grasping more scientific conceptions.

The intervention (HPIL) in itself includes a number of similarities with and differences from various other interventions and instructional approaches, such as peer instruction (PI), tutorials in introductory physics (tutorials), and cooperative group problem solving (CGPS) [4,25,32]. Like our intervention, PI and tutorials concentrate on improving students' conceptual understanding, while the emphasis in CGPS is on students' problem-solving abilities. In addition to conceptual understanding, tutorials also address students' scientific reasoning skills, which also play an essential role in our intervention when students have to argue in defense of their own ideas.

With regard to the context within which interventions are staged, our own intervention is implemented in a lecture setting like that used in PI, while tutorials and CGPS are staged in smaller groups of some 20 students. As in the case of tutorials and CGPS, our intervention is designed to supplement conventional lectures with separate sessions, whereas PI as an instructional approach is included within the lectures per se. Regarding duration, HPIL is compact in comparison to the other instructional approaches, requiring only a single hour supplementary to the conventional teaching. Hence, it is easy to include in any conventional lecture course on thermal physics.

The roles of the teacher and students are somewhat different in HPIL than in PI, tutorials, or CGPS. In HPIL, the teacher's role is to offer predesigned hints to the students, organize pair discussions, and take care of time allocation. This means that no special training or equipment such as clickers are needed, and a single teacher can manage the implementation without teaching assistants, even in the context of a large lecture course. In HPIL students work both individually and in pairs. The individual working phase, as with PI, ensures that a student has formulated preliminary personal ideas about the tasks prior to the following phases. First, the hinting phase is intended to enhance students' activation. Then, in the peer-interaction phase, students discuss in pairs, as in PI. In our own intervention the students discuss with freely chosen interlocutors, as in the case of PI and tutorials, and they do not have to adhere to particular certain roles (manager, skeptic, and checker or recorder) as in the CGPS sessions.

In summary, the intervention that we have devised has the extra value of combining a number of different types of aids in innovatory ways, and it can be implemented in any conventional course on thermal physics within a lecture setting without recourse to further training, special equipment, or teaching assistants.

\section{Implementation of the intervention}

The intervention took place in a lecture setting during a normal lecture time. The students had been informed beforehand about the intervention, but they had been given no details concerning the content or characteristics of the intervention. Participation was voluntary, and the proportion of students taking the intervention was approximately $65 \%$. Firstly, the students were permitted to take a diagnostic paper-and-pencil test (see Appendix C) individually [17]. This revealed the level of each student's ability to apply the content matter taught during preceding lectures and homework sessions. Secondly, with the aid of PowerPoint slides an instructor provided the students with a number of research-based content hints. The description of the hints together with a list of related misconceptions can be found in Appendix A. The hinting phase was conducted in two parts: a $p V$ diagram phase $\mathrm{A}$ and a content hint phase B, respectively. After an instructor showed the hints by PowerPoint, she asked students to review and reformulate their own answers. Thirdly, the students were asked to discuss their previous answers with a freely chosen pair of interlocutors and, where necessary, to reformulate their answers. In all intervention phases, the students wrote their answers on separate answer sheets.

An approximate time allocation for the intervention phases is found in Table II. In practice, the intervention was implemented during a lecture slot of two class periods (45 min each) so that approximately one hour was devoted to the intervention, while the rest of the time was used for

TABLE II. A time allocation for the HPIL teaching intervention.

\begin{tabular}{lc}
\hline Intervention phase & Approximate duration (min) \\
\hline 1. Individual working & 25 \\
2. Hinting phase A (a $p V$ diagram) & 8 \\
Hinting phase B (content hints) & 8 \\
3. Peer-interaction phase & $10-15$ \\
\hline \hline
\end{tabular}


conventional lecturing addressing other course content. The duration of the peer-interaction phase varied moderately since students were allowed to exit the lecture hall after finishing the intervention.

\section{METHODS}

\section{A. Participants}

The sample consisted of chemistry, mathematics, physics, and computer science majors. All of the participants had taken an introductory course in mechanics at university. The number of participants varied slightly in the pretesting and intervention and post-testing phases. Ten out of 75 participants had not taken a course in thermal physics at upper secondary school, but because no significant differences were observed between the subgroups, these have not been separately identified in the analysis.

\section{B. Data collection}

The data were collected at several points during the course so that a representative view of students' conceptions during the course could be obtained. The data collection phases are described in detail in the following subsections.

\section{Pretesting}

The test was implemented at the beginning of the course. The role of the pretesting was to reveal students' preknowledge regarding the first law of thermodynamics and thermal processes. This kind of information is essential in the evaluation of the influence of conventional teaching and intervention since the possible changes are difficult to assess without any information about students' preknowledge. In practice, in the paper-and-pencil test the students were asked to define the concepts of heat, work, and internal energy at the beginning of the first lecture in the course. In addition, a task extracted from a Finnish matriculation examination [33] was used to discover the students' ability to understand concepts concerning the thermal processes, to draw $p V$ diagrams, to understand the direction of heat transfer, and to interpret work in a cyclic process. Details of these tasks can be found in Appendix B.

The level of the task is appropriate for students who have taken a course dealing with thermal physics at upper secondary school. The terminology and phenomena required are familiar to the students because a Finnish matriculation exam is designed to address the content taught in the course of upper secondary studies.

\section{Intervention}

The intervention implemented after teaching played two distinct roles in the data collection. On the one hand, the first phase tested the students' abilities to apply the content taught in lectures and homework sessions. On the other hand, the subsequent intervention phases were designed to reveal possible changes in students' conceptions as a result of the intervention. The intervention was constructed on the basis of Meltzer's diagnostic test that deals with the three-phase process of an ideal gas [17]. A modified version of the diagnostic test that we used can be found in Appendix C.

In the course of the intervention, two separate methods were used for the data collection, namely, paper-and-pencil tests and audio recordings. All of the paper-and-pencil answers were analyzed to evaluate the ways in which misconceptions were changed in the course of the intervention. In the peer-interaction phase, the discussions of five voluntary pairs were recorded in order to obtain detailed and descriptive information about the students' explanations that would support the findings emerging from the written data. An instructor chose the pairs to be recorded based on their willingness to participate and also on her own familiarity with the cohort.

\section{Post-testing}

In order to test the permanence of the intervention, 2 weeks after the intervention we addressed the same themes again in the course exam. This was conducted by changing the direction of the cyclic process presented by Meltzer [17] and asking for similar tasks but with different wording. A set of tasks can be found in Appendix D. The aim was to discover whether overcoming misconceptions as a result of the intervention had lasted until the course exam, and secondly also to estimate the impact of selfstudy between the intervention and the course exam.

\section{Data analysis}

In the pretesting phase, the cohort was examined as a single entity $(N=75)$ in order to get an overview of students' conceptions concerning the whole cohort. Matched samples were examined in the intervention phase and the course exam $(N=65)$. This is because the intervention had been designed to overcome the kind of misconceptions that remained after lectures and homework sessions, and since the post-testing was implemented to gain an understanding of the permanence of the intervention, we included only students who had participated in both. ${ }^{4}$

In all of the data collection phases it was our aim to uncover students' conceptions. Hence, a categorization system was used that was similar in the pretesting, intervention, and post-testing phases. The categorization process was a combination of data-driven and theory-driven processes. As a result of the researchers' familiarity with previous research, the theory-driven process placed its greater emphasis on the formulation of categories. If students' responses included characteristics that did not fit into the categories that had been drawn on the basis of

\footnotetext{
${ }^{4}$ Participation in lectures is voluntary and hence not all of the students were present during all of the data collection phases.
} 
theory, they were categorized in a data-driven manner. Hence, the categorization process ended up being iterative in the sense that categories emerging from the data meant that the data already categorized had then been subjected to a second evaluation [34]. The categories were not necessarily exclusive, and hence in some tasks answers could be placed in more than one category. Where overlaps occurred, they are marked in the tables presenting the results. Generally, both blanks and irrelevant answers were placed in a category labeled "other or none."

The analysis of the audio recordings began by transcribing them into text documents. The discussions were analyzed by finding representative examples of pair discussions. After the discussion examples were selected, the process consisted of translation and compression phases, where the text was edited to render it readable.

\section{RESULTS}

The results are presented in three parts. The first section describes students' preconceptions based on their earlier education. The second section describes students' conceptions during the intervention, while the third section examines conceptions revealed in the course exam.

\section{A. Pretesting}

In the pretest, students were asked to explain what the concepts of heat, work, and internal energy mean and to describe them. The categories of answers are presented in Tables III-V. The rows and columns correspond to the same categories named only in rows, thus enabling an answer to be categorized into one or two categories simultaneously. Answers that belong to only one category have been placed on the diagonal of the table. Answers that include characteristics from two categories have been placed in the intersection of these categories. Hence, the categorization appears symmetrical with respect to the diagonal. The last column, "Total," presents the sum of all of the answers consigned to that category. The numbers may add up to more than $100 \%$ because of dual categorization. An example from each single category is presented after the category title so that the categorization criteria can be explained. A category "none" refers to blank answers, while the category of "other or none" may also include explanations that had remained uncategorized because their underlying idea could not be obtained. Blank answers were substantially more common than all other types of answers in this category.

TABLE III. Categorization of students' conceptions of heat. Categories A-D refer to the same categories in rows and columns. $N=75$. A typical example from each category is presented after the category symbol and title in italics.

\begin{tabular}{|c|c|c|c|c|c|}
\hline & A & B & $\mathrm{C}$ & D & Total \\
\hline $\begin{array}{l}\text { A. Amount of energy transferred } \\
\text { "Energy transferred due to a temperature difference" }\end{array}$ & $5 \%$ & $1 \%$ & $3 \%$ & $0 \%$ & $9 \%$ \\
\hline $\begin{array}{l}\text { B. References to thermal motion } \\
\text { "Motion of the particles" }\end{array}$ & $1 \%$ & $41 \%$ & $9 \%$ & $1 \%$ & $52 \%$ \\
\hline $\begin{array}{l}\text { C. A form of energy } \\
\text { "One form of energy" }\end{array}$ & $3 \%$ & $9 \%$ & $27 \%$ & $1 \%$ & $42 \%$ \\
\hline $\begin{array}{l}\text { D. Other or none } \\
\text { "A concept measured with a thermometer" }\end{array}$ & $0 \%$ & $1 \%$ & $1 \%$ & $11 \%$ & $13 \%$ \\
\hline
\end{tabular}

TABLE IV. Categorization of students' conceptions of work. Categories A-E refer to the same categories in rows and columns. $N=75$. A typical example from each category is presented after the category symbol in italics.

\begin{tabular}{|c|c|c|c|c|c|c|c|}
\hline & A & B & $\mathrm{C}$ & D & $\mathrm{E}$ & $\mathrm{F}$ & Total \\
\hline $\begin{array}{l}\text { A. Change or transfer of energy } \\
\text { "A quantity used to describe transferred energy" }\end{array}$ & $32 \%$ & $8 \%$ & $0 \%$ & $1 \%$ & $0 \%$ & $0 \%$ & $41 \%$ \\
\hline $\begin{array}{l}\text { B. Correct answers related to force } \\
\text { "Work means the product derived from force and displacement" }\end{array}$ & $8 \%$ & $32 \%$ & $0 \%$ & $0 \%$ & $1 \%$ & $0 \%$ & $41 \%$ \\
\hline $\begin{array}{l}\text { C. False dependencies } \\
\text { "A change occurring over a certain time", }\end{array}$ & $0 \%$ & $0 \%$ & $12 \%$ & $0 \%$ & $0 \%$ & $0 \%$ & $12 \%$ \\
\hline $\begin{array}{l}\text { D. The change in location } \\
\text { "Moving objects" }\end{array}$ & $1 \%$ & $0 \%$ & $0 \%$ & $5 \%$ & $0 \%$ & $0 \%$ & $6 \%$ \\
\hline $\begin{array}{l}\text { E. A form of energy } \\
\text { "Energy" }\end{array}$ & $0 \%$ & $1 \%$ & $0 \%$ & $0 \%$ & $1 \%$ & $0 \%$ & $2 \%$ \\
\hline F. None & $0 \%$ & $0 \%$ & $0 \%$ & $0 \%$ & $0 \%$ & $7 \%$ & $7 \%$ \\
\hline
\end{tabular}


TABLE V. Categorization of students' conceptions of internal energy. Categories A-C refer to the same categories in rows and columns. $N=75$. A typical example from each category is presented after the category symbol in italics.

\begin{tabular}{lccccr}
\hline \hline & $\mathrm{A}$ & $\mathrm{B}$ & $\mathrm{C}$ & $\mathrm{D}$ & Total \\
\hline $\begin{array}{l}\text { A. Energy related to the motion of particles } \\
\text { "The kinetic and potential energy of all particles" }\end{array}$ & $5 \%$ & $0 \%$ & $0 \%$ & $0 \%$ & $5 \%$ \\
$\begin{array}{l}\text { B. Energy of a system/energy stored within a system } \\
\text { "The energy inside a system" }\end{array}$ & $0 \%$ & $35 \%$ & $3 \%$ & $0 \%$ & $38 \%$ \\
$\begin{array}{l}\text { C. Mistaken energy conceptions } \\
\text { "Heat is one form of internal energy" }\end{array}$ & $0 \%$ & $3 \%$ & $13 \%$ & $0 \%$ & $16 \%$ \\
D. None & $0 \%$ & $0 \%$ & $0 \%$ & $44 \%$ & $44 \%$ \\
\hline \hline
\end{tabular}

\section{Conceptions of heat}

Table III shows that seven students out of 75 had a scientific view of heat corresponding to category A. Only two of these students explicitly mentioned that temperature difference is required for heat exchange. Great percentages in categories B and C indicated that heat is not regarded as a process quantity, and that it is confused with internal energy or thermal energy. Answers in category D included, for example, references to heat engines and confusion with temperature. Surprisingly, the latter instance was observed in only two answers, although it is reported to be a common misconception $[5,6,14,15]$.

\section{Conceptions of work}

Table IV reveals that the concept of work was described quite accurately, probably as a result of earlier university studies. Category A includes all answers stating that work changes energy or energy is required to do work. Category B includes mathematical and verbal descriptions based on mechanics that were correct but not stating anything about the relation of work to energy. A typical answer in category $\mathrm{C}$ revealed a confusion of the concepts of work and power. Answers in category D stated that work was related to transferring objects, but the answers omit any reference to force or energy. Students in category E claimed work to be a form of energy, but with no reference to its nature as a process quantity.

TABLE VI. Categorization of students' $p V$ diagrams concerned with three heat-absorbing thermal processes. $N=75$.

\begin{tabular}{lccc}
\hline \hline & Isochoric & Isobaric & Isothermal \\
\hline $\begin{array}{l}\text { A. Acceptable diagram } \\
\text { B. Acceptable diagram but } \\
\text { problems with direction }\end{array}$ & $13 \%$ & $13 \%$ & $4 \%$ \\
$\begin{array}{l}\text { C. Phenomenon is illustrated } \\
\quad \text { accurately but in a wrong }\end{array}$ & $4 \%$ & $13 \%$ & $15 \%$ \\
$\quad$ coordinate system & & & $0 \%$ \\
$\begin{array}{l}\text { D. Wrong diagram } \\
\text { E. Other or none }\end{array}$ & $5 \%$ & $5 \%$ & $17 \%$ \\
\hline \hline
\end{tabular}

\section{Conceptions of internal energy}

Results concerning internal energy in Table $\mathrm{V}$ show it to be a challenging concept for students. A great percentage in category $\mathrm{D}$ indicates that many students are unfamiliar or very unsure about the concept. Correct answers stating internal energy to be a measure of the energy of particles have been categorized in category $\mathrm{A}$. The answers in category B are not false, but they leave the concept ambiguous because the nature of energy has not been specified. Answers in category $\mathrm{C}$ include inadequate microscopiclevel explanations and inaccurate references to enthalpy or macroscopic potential energy.

\section{First law of thermodynamics and thermal processes}

Students' understanding of thermal processes and the first law of thermodynamics was examined by using a set of tasks utilized in the Finnish matriculation examination in the Fall of 2011 [33], but with minor modifications regarding wording. Thus, the level of difficulty of the tasks should be appropriate because a majority of the students had taken a course in thermal physics in upper secondary school. The tasks can be found in Appendix B.

The first task was to draw $p V$ diagrams for heatabsorbing isochoric, isobaric, and isothermal processes with an arrow indicating the process direction. The students' drawings were categorized into four exclusive categories, every process individually. Table VI shows the categorization.

Acceptable answers in category A included correct curves with arrows indicating the direction of processes. ${ }^{5}$ Answers in category B included similar graphs with absent or erroneous process directions. Answers in category C utilized incorrect coordinates but visualized the phenomenon correctly, with or without a direction. The trend in these responses was to utilize $p T$ diagrams for an isochoric process and $V T$ diagrams for an isobaric process: the coordinate axes were replaced so that these coordinate

\footnotetext{
${ }^{5}$ Isothermal processes were considered to be correct even if the curve did not follow the exact shape: descending straight lines were also accepted.
} 
quantities would not remain constant. Category D included answers where the shape of the curve was wrong in some way. For example, the isochoric process was illustrated using a figure drawn from an isothermal process. Responses in category E were mostly absent: 42 out of 49 students did not write or draw anything. Other responses in that category included the introduction of the ideal gas law or the introduction or speculation about the meanings of the terms isochoric, isobaric, and isothermal processes, but no figures were drawn.

The first comment that can be made about the results presented in Table VI is that only $36 \%$ of the students drew diagrams that could be considered to be relevant attempts. This indicates that a majority of students had no real idea about the phenomena related to the concepts, as explicitly described in writing by some of the students. A modest percentage of correctly shaped diagrams to be seen in categories A and B suggest that thermal processes are not familiar to students despite their upper secondary school studies. Problems with the directions in category B suggest that students were unable to understand heat transfer even if the thermal processes themselves were familiar. Although the size of category $\mathrm{C}$ is small, in a sense it is significant that university students may not follow or fully understand the instructions. With regard to category D, errors concerning isochoric and isobaric processes followed no specific trend. In the case of an isothermal process, $15 \%$ of the students drew a straight line with an ascending trend, indicating that they considered pressure and volume to be directly proportional.

Question B (see Appendix B) concerning the combination of three processes to reach a maximal net work demonstrated unambiguously that students had no idea of how to interpret work in a cyclic process. The results can be summarized by pointing out that only one student out of 75 mentioned that the limited area should be maximized, but even he claimed this to be only a guess, although admittedly a lucky one. None of the students could produce an acceptable figure, with only one being close, leading to the conclusion that students are unable to interpret work in the context of thermodynamics by means of $p V$ diagrams.

\section{Summary of the pretest}

Based on students' answers in the pretests, we conclude that in the course of their previous studies a majority of the students tested had not grasped the essential thermal physics content. Students' definitions for three essential concepts regarding the first law of thermodynamics revealed that students not only lack the essential knowledge, but that they also hold various misconceptions. Their definitions concerning heat indicate that they do not distinguish it from internal energy. Work, again, is described well in terms of mechanics, but students' answers do not reflect any ideas concerning how to apply it to a thermal physics content. Internal energy seems to be a concept described on the basis of its appearance, but its physical meaning appears not to be evident for students.

Findings regarding thermal processes revealed that students are unfamiliar with the requisite terminology and the dependencies between quantities. Moreover, $p V$ diagrams were not used successfully in determining the direction of heat transfer or work. Based on these findings, we conclude that upper secondary education does not guarantee an adequate understanding of concepts, a major factor that needs to be taken into account in university teaching by paying explicit attention to inadequate preknowledge.

\section{B. Intervention}

Students' categorized explanations regarding seven multiple-choice questions (Appendix C) used in the intervention are presented in Tables VII-XIII, including the question topics. The first category presented in the tables is the preferred scientific one, while the subsequent categories indicate that students have misconceptions or other types of problems. The number preceding the category symbol refers to the question number. In order to explain the nature of responses in all categories, examples demonstrating each of the categories are presented after the category titles. Explanations categorized in "other or none" were either absent or the ideas underlying them could not be determined.

Rather than the emphasis being placed on the students' selections in the multiple choices, it is on their conceptions, which were evaluated by analyzing the explanations that they provided. The explanations were categorized independently of the multiple-choice selections that the students had made. The percentages related to the students' correct multiple-choice selections in the tasks are presented in order to illustrate the various ways in which correct answers could be achieved, despite being accompanied by inaccurate explanations. The number of students using accurate explanations but ending up with incorrect multiple-choice selections was relatively small (on average $2 \%$, with a highest rate at $6 \%$ ), and hence those have been are excluded from the discussion.

Selected quotations from recorded peer discussions are also introduced in order to demonstrate the kind of explanations that students used in their discussions. Our intention has been to present representative examples of the discussions, not to concentrate on those that simplistically include the desired outcome. Deleted sections are marked with (...), and researchers' notations and insertions are presented within square brackets []. In order to facilitate comprehension of the peer discussion examples, the correct items in the multiple-choice questions are also presented in the tables.

\section{Work in an isobaric process}

Table VII presents students' categorized explanations regarding question 1, which addresses the work in an 
TABLE VII. Students' categorized explanations regarding the work in an isobaric expansion process. $N=65$. An example from each category is presented after the category symbol in italics.

\begin{tabular}{|c|c|c|c|c|}
\hline \multirow[b]{2}{*}{ Students' explanations } & \multicolumn{4}{|c|}{ Intervention phase } \\
\hline & $\begin{array}{l}\text { Individual } \\
\text { working }\end{array}$ & $\begin{array}{l}p V \text { diagram } \\
\text { hint }\end{array}$ & $\begin{array}{l}\text { Content } \\
\text { hints }\end{array}$ & $\begin{array}{l}\text { Peer } \\
\text { interaction }\end{array}$ \\
\hline $\begin{array}{l}\text { 1A. Work is done by gas because its volume increases (correct choice B) } \\
\text { "Because the gas has expanded, work is done by the gas on the environment" }\end{array}$ & $52 \%$ & $55 \%$ & $57 \%$ & $80 \%$ \\
\hline $\begin{array}{l}\text { 1B. Heat and work are not distinguished } \\
\text { "Gas is heated } \Rightarrow \text { it absorbs heat, so work is done on the gas", }\end{array}$ & $22 \%$ & $17 \%$ & $14 \%$ & $12 \%$ \\
\hline $\begin{array}{l}\text { 1C. Direction of work is misunderstood } \\
\text { "Volume is increased } \Rightarrow \text { work is done by the environment on the gas" }\end{array}$ & $20 \%$ & $22 \%$ & $20 \%$ & $5 \%$ \\
\hline $\begin{array}{l}\text { 1D. Confusing processes } \\
\text { " } E_{\text {th }} \text { is the same initially and finally. Heat } Q \text { increases, so work } W \text { has } \\
\text { to be negative" }\end{array}$ & $3 \%$ & $3 \%$ & $5 \%$ & $0 \%$ \\
\hline $\begin{array}{l}\text { 1E. Other or none } \\
\text { " } d W<0 "\end{array}$ & $3 \%$ & $3 \%$ & $5 \%$ & $3 \%$ \\
\hline
\end{tabular}

isobaric expansion process. It can be seen that the percentage of correct explanations increased in the course of the peer-interaction phase. The misconceptions concerning direction of work, in category $\mathrm{C}$, and confusing processes, in category $\mathrm{D}$, were overcome well, but the intervention provided no very useful help in distinguishing between work and heat in category B. Surprisingly, the content hint had little effect on the number of answers categorized in category $\mathrm{B}$, although the definitions that would be needed to distinguish between the concepts had been introduced.

With respect to the correct multiple-choice selections, their percentages increased in the course of the intervention: the respective percentages in the different intervention phases were $60 \%, 62 \%, 63 \%$, and $82 \% .87 \%, 88 \%, 85 \%$, and $98 \%$ of the students making a correct multiple-choice selection also explained the task accurately. Students who made the correct choice but gave inaccurate explanations either misunderstood the direction of the work or described the process inaccurately, referring to increasing pressure or constant thermal energy, for example.

In this question, the contribution of the audio recordings was only slight because all but one pair of those recorded agreed about the correct explanation before their discussions. The discussion between the disagreeing pair, Chip and Dale, proceeded as follows.

Chip H'mm. The work is done by the gas on the environment when the volume is increased, so this time the work is done by the gas.

Dale Oh yeah, so it is. Apparently, I've been looking at this inaccurately. Well, most certainly it is not $C$. Yeah, it's B. I've been looking at this figure wrongly.

This time, a single sentence from Chip alerted Dale to observe a careless mistake in his answer and hence helped him to reach a correct conclusion with an accurate explanation.

\section{Change in the kinetic energy of particles in an isobaric process}

Table VIII shows results connected with change in the kinetic energy of particles in an isobaric expansion process. Following the conclusion of the lectures and homework sessions, the number of correct explanations was very small, even though the direction of the work had been understood well in the previous task. The content hints increased the percentages of correct explanations by a modest amount, but their percentages had been increased from $15 \%$ to $26 \%$ during the peer-interaction phase. A surprising result is the large increase in answers included in category $\mathrm{E}$ as a result of the content hints. Based on the large percentages in categories B and $\mathrm{E}$ and in their combinations, it would seem that, even after the intervention, work as transferred energy was still poorly understood.

In this task the students' correct multiple-choice percentages in the course of the intervention were as follows: $29 \%, 31 \%, 23 \%$, and $35 \%$. Out of these students, the percentage providing correct explanations changed as follows: $32 \%, 40 \%, 60 \%$, and $61 \%$. During the first three phases of the intervention, $20 \%-32 \%$ of the students making a correct multiple-choice selection were categorized in $2 \mathrm{C}$ and $13 \%-6 \%$ in $2 \mathrm{E}$. In the peer-interaction phase the percentages were $9 \%(2 \mathrm{C})$ and $22 \%(2 \mathrm{E})$. These findings indicate that the correct multiple-choice selection can be achieved with inaccurate explanations in this specific task, as has also been shown by Meltzer [17].

This task stimulated fruitful discussions among four recorded pairs, and two of these managed to reach a correct conclusion using accurate explanations. An example follows.

Selma I thought the answer must be A, B, or C. It [the kinetic energy of particles] has to increase. But I couldn't explain why.

Patty It's like when $e_{\text {avg }}$ equals $3 / 2$ times $k_{b} T$ and $T$ has increased. Or has it? I guess it 
TABLE VIII. Students' categorized explanations regarding change in the kinetic energy of particles in an isobaric expansion process. $N=65$. A typical example from each category is presented after the category symbol in italics.

\begin{tabular}{|c|c|c|c|c|}
\hline \multirow[b]{2}{*}{ Students' explanations } & \multicolumn{4}{|c|}{ Intervention phase } \\
\hline & $\begin{array}{l}\text { Individual } \\
\text { working }\end{array}$ & $\begin{array}{l}p V \text { diagram } \\
\text { hint }\end{array}$ & $\begin{array}{l}\text { Content } \\
\text { hints }\end{array}$ & $\begin{array}{l}\text { Peer } \\
\text { interaction }\end{array}$ \\
\hline $\begin{array}{l}\text { 2A. Part of the energy is used to do work (correct choice C) } \\
\text { "Energy is also used to increase volume" }\end{array}$ & $11 \%$ & $12 \%$ & $15 \%$ & $26 \%$ \\
\hline $\begin{array}{l}\text { 2B. The impact of work on energy is neglected } \\
\text { "The energy absorbed goes to the kinetic energy of particles as a whole" }\end{array}$ & $32 \%$ & $35 \%$ & $29 \%$ & $26 \%$ \\
\hline $\begin{array}{l}\text { 2C. Not all of the heat is converted into the kinetic energy of particles; } \\
\text { no correct explanation } \\
\text { "Not all of the heat absorbed converts into kinetic energy" }\end{array}$ & $12 \%$ & $11 \%$ & $8 \%$ & $5 \%$ \\
\hline $\begin{array}{l}\text { 2D. Wrong dependencies } \\
\text { "The volume increases, in which case the total energy decreases by } x \text { Joules" }\end{array}$ & $9 \%$ & $9 \%$ & $5 \%$ & $3 \%$ \\
\hline $\begin{array}{l}\text { 2E. Answers referring to the dependency of temperature and the kinetic } \\
\text { energy of particles }\end{array}$ & $9 \%$ & $8 \%$ & $22 \%$ & $26 \%$ \\
\hline $\begin{array}{l}\text { "The temperature rises, which means that the gas molecules move } \\
x \text { Joules more" }\end{array}$ & & & & \\
\hline $\begin{array}{l}\text { 2F. Combination of } 2 \mathrm{~B} \text { and } 2 \mathrm{E} \\
\text { "The gas absorbs heat when the temperature increases, and the kinetic } \\
\text { energy of the particles increases" }\end{array}$ & $5 \%$ & $5 \%$ & $3 \%$ & $0 \%$ \\
\hline $\begin{array}{l}2 \mathrm{G} . \text { Combination of } 2 \mathrm{~B}, 2 \mathrm{C} \text {, and } 2 \mathrm{E} \\
\text { " } \Delta E_{\text {th }}=Q . \text { The kinetic energy increases because the temperature increases. } \\
\text { However, the increase is less than } x \text { Joules because part of the } x \text { Joules } \\
\text { increase the temperature and part of it increases the kinetic energy" }\end{array}$ & $0 \%$ & $0 \%$ & $0 \%$ & $3 \%$ \\
\hline $\begin{array}{l}\text { 2H. Other or none } \\
\text { "Closed system } \Rightarrow \text { heat does not escape" }\end{array}$ & $22 \%$ & $20 \%$ & $18 \%$ & $11 \%$ \\
\hline
\end{tabular}

[temperature] has to increase because it [the gas] was heated.

Selma The net kinetic energy has to increase because it [the gas] has been heated but how do you know if it increases by more than $x$ joules, by $x$ joules, or by less than $x$ joules?

Patty Well, I just made up that it would equal $x$ joules.

Selma This is how I thought of it: now that the work in AB process is...

Patty Negative

Selma ... Negative, less than zero. So if you turn this equation like this, it becomes $\Delta E_{\mathrm{th}}-Q$. Now, this $Q$ equals $x$ joules

Patty This is less than zero

Selma No; the work is smaller than zero. (...) And then $\Delta E_{t h}-Q$ has to be less than zero. (...) And when this [heat] was $x$ joules, then this [the kinetic energy of particles] has to be less than $x$ joules, so it becomes negative

Patty Yeah. So this has to be less than $x$

Selma And so I concluded that the answer has to be C. So it will increase, but by less than $x$ joules

Patty Okay, C it is. I now understand it, but I didn't manage to think it through in so difficult a way myself.
Patty's idea about concentrating only on the change in temperature was corrected during her discussion with Selma. The dialogue shows that even if Selma was leading the discussion, Patty also participated in the discussion with interjections that indicates that Patty followed Selma's explanation.

\section{Change in the kinetic energy of particles in an isothermal process}

Table IX shows that content hints and peer interaction helped students to produce accurate explanations when asked about the kinetic energy of particles in an isothermal compression process. Category $3 \mathrm{~B}$ includes explanations where the kinetic energy of the particles was linked to the volume or pressure. In category $3 \mathrm{C}$, the process is understood inaccurately in one way or another. Misconceptions related to misunderstanding process properties seen in categories $C$ and $D$ were corrected well during discussions, but erroneous dependencies in category B remained relatively common, although reduced in number; students tended to equate the kinetic energy of particles with pressure or volume.

The percentages of the students' correct multiple-choice selections in this task changed as follows during the intervention: $57 \%, 58 \%, 68 \%$, and $85 \% .89 \%, 89 \%, 91 \%$, and $89 \%$ of these students also provided accurate explanations, while other students making a correct multiple-choice 
TABLE IX. Students' categorized explanations regarding change in the kinetic energy of particles in an isothermal compression process. $N=65$. A typical example from each category is presented after the category symbol and title in italics.

\begin{tabular}{|c|c|c|c|c|}
\hline \multirow[b]{2}{*}{$\underline{\text { Students' explanations }}$} & \multicolumn{4}{|c|}{ Intervention phase } \\
\hline & $\begin{array}{l}\text { Individual } \\
\text { working }\end{array}$ & $\begin{array}{l}p V \text { diagram } \\
\text { hint }\end{array}$ & $\begin{array}{l}\text { Content } \\
\text { hints }\end{array}$ & $\begin{array}{l}\text { Peer } \\
\text { interaction }\end{array}$ \\
\hline $\begin{array}{l}3 \mathrm{~A} \text {. Temperature stays constant, therefore the kinetic energy of the particles } \\
\text { stays constant (correct choice C) } \\
\text { "The kinetic energy of the particles remains constant because the temperature } \\
\text { remains constant" }\end{array}$ & $51 \%$ & $52 \%$ & $62 \%$ & $77 \%$ \\
\hline $\begin{array}{l}\text { 3B. The kinetic energy of the particles is linked to the volume or pressure } \\
\text { "The total kinetic energy increases when the pressure increases" }\end{array}$ & $26 \%$ & $25 \%$ & $17 \%$ & $15 \%$ \\
\hline $\begin{array}{l}\text { 3C. Other problems with the process } \\
\text { "No work is done on the system, and no heat is transferred between the system } \\
\text { and the environment" }\end{array}$ & $3 \%$ & $5 \%$ & $6 \%$ & $2 \%$ \\
\hline $\begin{array}{l}\text { 3D. Work increases thermal energy and the kinetic energy of the particles } \\
\text { "Work has been done } \Rightarrow \text { energy increases" }\end{array}$ & $8 \%$ & $6 \%$ & $6 \%$ & $3 \%$ \\
\hline $\begin{array}{l}\text { 3E. Other or none } \\
\text { "The kinetic energy remains the same even if the volume changes" }\end{array}$ & $12 \%$ & $11 \%$ & $9 \%$ & $3 \%$ \\
\hline
\end{tabular}

selection used explanations categorized in 3E (no explanation) or $3 \mathrm{C}$ referring to erroneous process properties.

Discussions recorded in this task provided no dialogue in which a student with an inaccurate explanation was persuaded to change their answer to the correct one; all but one recorded pair agreed with the explanation even if it was not the desired one. Compare an example of students in agreement but using inaccurate explanations.

Sheila Question three. What did you answer? I have A. Gerald So do I.

Sheila What about your explanation? Mine says "Because the volume is decreased and the temperature remains constant, the pressure inside the cylinder increases. When the pressure increases, the net kinetic energy also increases."

Gerald Well, I have basically the same. When the volume is reduced, the pressure increases and the particles move and collide more, and hence the net kinetic energy increases.

The discussion shows that the impact of discussions is dependent on the initial conceptions held by the students. If students agree on some misconception (now category 3B), it is unlikely that they will end up with a correct scientific explanation since their conceptions will remain unchallenged.

\section{Heat in an isothermal compression process}

The heat in an isothermal process (Table X) turned out to be a problematic topic. The percentage of scientific explanations was essentially unchanged during the intervention. The percentage of misconceptions remained almost constant throughout the intervention. This indicates that students were strongly influenced by the apparent absence of any temperature difference between the gas and the water and could not analyze the situation from the viewpoint of the first law of thermodynamics. However, these two are not contradictory if the nature of the isothermal process with differential temperature difference between system and surroundings is understood accurately.

The changes in the percentages of students' correct multiple-choice selections in the course of the intervention changed as follows: $46 \%, 48 \%, 49 \%$, and $32 \%$. Of these students, $63 \%, 64 \%, 72 \%$, and $71 \%$ gave accurate explanations. Explanations from students making a correct selection but producing inaccurate explanations were distributed evenly across all of the categories. 49\%-63\% of the students made a multiple-choice selection claiming that the heat equaled zero under isothermal conditions, and $80 \%-88 \%$ of these students were categorized in $4 \mathrm{~B}$ or $4 \mathrm{C}$.

Peer discussions in this particular task revealed students' uncertainty about their answers. Some students mentioned their uncertainty explicitly and other discussions revealed inconsistencies. The example below is from a pair whose responses preceding the peer-interaction phase were categorized in 4A (Daisy) and 4D (Brigitta).

Brigitta I answered B. And it [heat] is transferred from the water to the gas.

Daisy I also answered B, and "from the gas to the water"

Brigitta Well, I thought that $p V$ equals $n R T$ and the volume decreases when those weights are placed, right? So this will decrease. Well, I honestly don't know, but this means that the temperature decreases, right?

Daisy But the temperature remains the same

Brigitta Yeah, but what if we had an insulated system. Then the temperature would decrease, or would it? No 
TABLE X. Students' categorized explanations regarding the heat in an isothermal compression process. $N=65$. A typical example from each category is presented after the category symbol in italics.

\begin{tabular}{|c|c|c|c|c|}
\hline \multirow[b]{2}{*}{ Students' explanations } & \multicolumn{4}{|c|}{ Intervention phase } \\
\hline & $\begin{array}{l}\text { Individual } \\
\text { working }\end{array}$ & $\begin{array}{l}p V \text { diagram } \\
\text { hint }\end{array}$ & $\begin{array}{l}\text { Content } \\
\text { hints }\end{array}$ & $\begin{array}{c}\text { Peer } \\
\text { interaction }\end{array}$ \\
\hline $\begin{array}{l}\text { 4A. Internal energy stays constant, therefore heat has to be transferred from gas } \\
\text { to water (correct choice B) }\end{array}$ & $29 \%$ & $31 \%$ & $35 \%$ & $28 \%$ \\
\hline \multicolumn{5}{|l|}{$\begin{array}{l}\text { "The temperature does not increase, and hence } \Delta E_{t h}=W-Q=0, W=Q \text {, } \\
\text { heat is transferred to the water" }\end{array}$} \\
\hline $\begin{array}{l}\text { 4B. No energy flow, since there is no temperature difference between the } \\
\text { gas and the water }\end{array}$ & $15 \%$ & $14 \%$ & $14 \%$ & $20 \%$ \\
\hline \multicolumn{5}{|l|}{ "The water and gas are in thermal equilibrium" } \\
\hline $\begin{array}{l}\text { 4C. No energy flow, since there is no change in the temperature or energy } \\
\text { "Because the temperature stays constant" }\end{array}$ & $28 \%$ & $29 \%$ & $29 \%$ & $29 \%$ \\
\hline $\begin{array}{l}\text { 4D. Erroneous dependencies } \\
\text { "Heat is transferred into the water because the volume of the gas is reduced" }\end{array}$ & $3 \%$ & $3 \%$ & $3 \%$ & $5 \%$ \\
\hline $\begin{array}{l}\text { 4E. Combination of } 4 \mathrm{~A} \text { and } 4 \mathrm{D} \\
\text { "When the pressure is increased according to the ideal gas law, the } \\
\text { temperature should also increase. For the temperature to remain constant, } \\
\text { the gas has to give out energy into the water" }\end{array}$ & $5 \%$ & $5 \%$ & $5 \%$ & $0 \%$ \\
\hline $\begin{array}{l}\text { 4F. Combination of } 4 \mathrm{~B} \text { and } 4 \mathrm{C} \\
\text { "If the temperature of gas remains constant during the process } B C \text {, there is no } \\
\text { temperature difference, and hence no heat is transferred" }\end{array}$ & $3 \%$ & $3 \%$ & $3 \%$ & $3 \%$ \\
\hline $\begin{array}{l}\text { 4G. Other or none } \\
\text { "Energy is transferred from gas to water because situation is reverse to process } \\
A B \text { where gas absorbed energy from water" }\end{array}$ & $17 \%$ & $15 \%$ & $11 \%$ & $15 \%$ \\
\hline
\end{tabular}

(...) [discussion about pressure, volume, temperature, and the ideal gas law]

Brigitta So, basically, the temperature remains constant. So is it [heat] transferred?

Daisy Well, I think it should be. Wouldn't the temperature increase if there wasn't any [heat transfer included]

Brigitta Well, that's what one would think

Daisy And because it [temperature] remains the same, heat has to be transferred away from there [the gas]. Isn't there a temperature difference between the gas and the surroundings?

Brigitta I guess so. Well, should we put that heat is transferred from the gas to the water?

Daisy Yes, somewhere, but which way? If more energy is placed here inside.

Brigitta Well, it would not make any sense. So let's put B and...

Daisy "From the gas to the water," right?

Brigitta "From the gas to the water." And then our explanation. (...) Well, this decreases and that increases [referring to the ideal gas law]; it doesn't make any sense. You cannot [explain] it with this equation; we should use something else.

Daisy I don't know how to work it out.

Brigitta "No explanation"
Daisy's explanations after ideal gas law discussions were accurate, even though she was not directly referring to the first law of thermodynamics. Brigitta and Daisy managed to apply the idea of escaping heat to compensate for the impact of work on the kinetic energy of particles and temperature, and they reached the correct conclusion. In addition, they realized that the ideal gas law could not be used to explain their answer. They were unable, however, to put their explanations into words, and hence they did not provide any written explanation at all.

\section{Heat in an isochoric process}

Table XI shows students' categorized responses in a task addressing the heat in an isochoric process. The answers in categories A and B could be considered acceptable ones but they are separated because those provided by category B can also be achieved even with an inadequate understanding of the topic. ${ }^{6}$ Following the intervention, the percentage of accurate explanations remained low. A big increase may be observed in the case of category $\mathrm{C}$, however, which nevertheless cannot be considered to be a precise

\footnotetext{
${ }^{6}$ Support for this inference is provided by comparing students' explanations regarding a previous task. Out of the 19 students who provided the category-B explanation in this (isochoric compression) task, only one student had provided an appropriate explanation for the isobaric expansion process (question number 2; see Table VIII.
} 
TABLE XI. Students' categorized explanations regarding heat in an isochoric process. $N=65$. A typical example from each category is presented after the category symbol in italics.

\begin{tabular}{|c|c|c|c|c|}
\hline \multirow[b]{2}{*}{ Students' explanations } & \multicolumn{4}{|c|}{ Intervention phase } \\
\hline & $\begin{array}{l}\text { Individual } \\
\text { working }\end{array}$ & $\begin{array}{l}p V \text { diagram } \\
\text { hint }\end{array}$ & $\begin{array}{l}\text { Content } \\
\text { hints }\end{array}$ & $\begin{array}{l}\text { Peer } \\
\text { interaction }\end{array}$ \\
\hline $\begin{array}{l}\text { 5A. All energy leaves gas as heat; no work is done (correct choice F) } \\
\text { "For an isochoric process } W=0 \text {, so } \Delta E_{t h}=-Q \text { " }\end{array}$ & $12 \%$ & $12 \%$ & $15 \%$ & $18 \%$ \\
\hline $\begin{array}{l}\text { 5B. Correct, but with no mention of work equaling zero (partially correct) } \\
\text { "Molecules lose energy by the amount that water absorbs" }\end{array}$ & $28 \%$ & $28 \%$ & $31 \%$ & $23 \%$ \\
\hline $\begin{array}{l}\text { 5C. Temperature decreases, so the kinetic energy of the particles decreases } \\
\text { (partially correct) } \\
\text { "The total kinetic energy decreases because the temperature decreases" }\end{array}$ & $17 \%$ & $15 \%$ & $20 \%$ & $31 \%$ \\
\hline $\begin{array}{l}\text { 5D. Problems with energy } \\
\text { "Energy will remain unchanged: the first law of thermodynamics" }\end{array}$ & $17 \%$ & $17 \%$ & $11 \%$ & $9 \%$ \\
\hline $\begin{array}{l}\text { 5E. Combination of } 5 \mathrm{~B} \text { and } 5 \mathrm{C} \\
\text { "Because the temperature decreases, the kinetics of the particles decreases. } \\
\text { Because energy cannot be lost, transferred energy is the same as energy } \\
\text { absorbed by water" }\end{array}$ & $2 \%$ & $2 \%$ & $2 \%$ & $2 \%$ \\
\hline $\begin{array}{l}\text { 5F. Combination of } 5 \mathrm{C} \text { and } 5 \mathrm{D} \\
\text { "The temperature decreases, y Joules is transferred as heat and } \\
\text { kinetic energy" }\end{array}$ & $0 \%$ & $0 \%$ & $2 \%$ & $2 \%$ \\
\hline 5G. None & $25 \%$ & $26 \%$ & $20 \%$ & $11 \%$ \\
\hline
\end{tabular}

explanation category since the reduction in temperature cannot explain the exact value of the energy decrease. On the other hand, the misconceptions observable in the case of category D, including, for example, references to the potential energy and "energy loss" of particles, were partly overcome in the course of the intervention.

In this task the percentages of students' accurate explanations were significantly lower than those corresponding to the correct multiple-choice selections; the latter were $62 \%$, $63 \%, 65 \%$, and $77 \%$. This difference may be explained by the fact that, as a result of our strict criterion for obtaining an accurate explanation, many explanations producing a correct prediction are categorized in $5 \mathrm{~B}$ and $5 \mathrm{C}$, with the reasons explained above. Thus, only a minority $(10 \%, 10 \%, 14 \%$, and $24 \%)$ of students making a correct multiple-choice selection were categorized in 5A. Most of the students who made the correct multiple-choice selection were categorized in the partially correct categories $5 \mathrm{~B}$ or $5 \mathrm{C}$. Other students who made a correct selection explicitly claimed that this situation was similar to that introduced in task 2 addressing heat in isobaric process or provided no explanations. These findings reveal that correct selections may not describe the level of students' knowledge accurately, especially if the correct selection can be achieved with the aid of inadequate explanations.

In this question, the recorded discussions between students varied between perfect consensus and lively disagreement. The following discussion has been taken from that of an insecure pair disagreeing initially about the correct answer.
Sheila This was a bit of a guess. What did you answer? Gerald I answered D.

Sheila I have F. I thought that in the other one [question 2] addressing [the process] from A to $B$, they also asked [about the kinetic energy change of particles]. There was this "part of the heat is used to expand." Here's nothing. The volume remains the same. But I don't know for sure.

Gerald Well, I reasoned it out by explaining that the temperature remains constant.

Sheila Don't pressure or volume have an influence?

Gerald Well, they gave us the equation that the energy of the monatomic gas is affected only by temperature

Sheila Was it heat or what...

Gerald The amount of thermal energy remains unchanged. No, the amount of thermal energy is affected only by temperature.

Sheila But they are asking about kinetic energy here. What's that? I am confused by all these.

Gerald Well, doesn't it describe temperature change? So, the more thermal energy there is, the more they [particles] move.

Sheila Okay.

Gerald I don't know for sure.

Sheila I couldn't answer a thing so I guess I'll count on you.

Sheila was right in her first explanation but expressed her uncertainty. Gerald's explanations and understanding of the physical situation were erroneous, but Sheila could 
TABLE XII. Students' categorized explanations regarding the net work done in a cyclic process. $N=65$. A typical example from each category is presented after the category symbol and title in italics.

\begin{tabular}{|c|c|c|c|c|}
\hline \multirow[b]{2}{*}{ Students' explanations } & \multicolumn{4}{|c|}{ Intervention phase } \\
\hline & $\begin{array}{c}\text { Individual } \\
\text { working }\end{array}$ & $\begin{array}{l}p V \text { diagram } \\
\text { hint }\end{array}$ & $\begin{array}{l}\text { Content } \\
\text { hints }\end{array}$ & $\begin{array}{c}\text { Peer } \\
\text { interaction }\end{array}$ \\
\hline $\begin{array}{l}\text { 6A. Comparing magnitudes of work in subprocesses (correct choice A) } \\
\text { "It is seen from the } p V \text {-diagram sketch that } W_{a b}<0, W_{b c}>0, W_{c a}=0 \text {, } \\
\text { and }\left|W_{b c}\right|>\left|W_{a b}\right| \text {, so the net work is greater than } 0 "\end{array}$ & $28 \%$ & $35 \%$ & $40 \%$ & $51 \%$ \\
\hline $\begin{array}{l}\text { 6B. Same initial and final states/Volume does not change } \\
\text { "States A and D are the same so the net work is } 0 "\end{array}$ & $28 \%$ & $26 \%$ & $26 \%$ & $29 \%$ \\
\hline $\begin{array}{l}\text { 6C. Direction of work is misunderstood } \\
\text { "The negative part of the work is greater" }\end{array}$ & $6 \%$ & $8 \%$ & $9 \%$ & $5 \%$ \\
\hline $\begin{array}{l}\text { 6D. The whole process is not observed } \\
\text { "Work is done on the gas when adding weights, so } W>0 "\end{array}$ & $3 \%$ & $3 \%$ & $3 \%$ & $2 \%$ \\
\hline $\begin{array}{l}\text { 6E. Work is considered to be equal in isobaric and isothermal processes } \\
\text { "First, work is done by the gas. Then, the same work is done by the } \\
\text { environment. No work is done during the final phase" }\end{array}$ & $8 \%$ & $5 \%$ & $3 \%$ & $3 \%$ \\
\hline $\begin{array}{l}\text { 6F. Combination of } 6 \mathrm{~B} \text { and } 6 \mathrm{E} \\
\text { "The gas is expanded }(W<0) \text { and compressed }(W>0) \text { back to its initial } \\
\text { state" }\end{array}$ & $2 \%$ & $2 \%$ & $2 \%$ & $3 \%$ \\
\hline $\begin{array}{l}\text { 6G. Other or none } \\
\text { "Work done is larger than } 0 \text { even if we are back at the initial state" }\end{array}$ & $26 \%$ & $22 \%$ & $17 \%$ & $8 \%$ \\
\hline
\end{tabular}

not detect the flaw in them and they ended up giving an incorrect explanation.

\section{Net work in a cyclic process}

The results regarding the net work done in a cyclic process presented in Table XII reveal that the intervention can be effective in terms of increasing the percentage of correct explanations. A hint about a $p V$ diagram designed to help in this particular question helped $7 \%$ of the students to reach a correct explanation. Content hints containing a definition of work and peer interaction also helped some of the students, with the result that half of the students were eventually able to reason through the task correctly. It was apparent that students were sometimes reluctant to change a commonly held misconception concerning the same initial and final states in category B. The explanations in categories $6 \mathrm{~B}$ and $6 \mathrm{E}$ are connected to the item in the multiple-choice selection stating that the net work done during a cyclic process is equal to zero.

With respect to the students' correct multiple-choice selections, the students scored 46\%, 51\%, 52\%, and 58\% during the intervention phases, respectively. Of these students, the percentages also providing accurate explanations changed as follows: $60 \%, 66 \%, 71 \%$, and $82 \%$. With respect to the students making a correct selection but with inaccurate explanations, the emphasis was on the answers categorized in $6 \mathrm{G}$ and $6 \mathrm{D}$.

An example of the positive impact of the peer discussions can be seen in the following sample.
Sheila Then question number six. Net work. This was an easy one; I answered A.

Gerald I have B but probably it was A, if you find it easy.

Sheila I drew this kind of $p V$ diagram.

Gerald Okay, is it similar?

Sheila Yes.

Gerald Yes.

Sheila From $A$ to $B$, work is negative because the volume increases. From $B$ to $C$ it [work] is positive. And this positive area is bigger than the negative area. So the work is positive.

Gerald Isn't the work from A to B negative?

Sheila Yes.

Gerald And positive from $B$ to $C$. Yes.

Sheila But the area is bigger here than there [referring to the $p V$ diagram]

Gerald Well, that's right. But what was the question?

Sheila The net work was asked about, during the whole process.

Gerald Yup, it's A, clearly. (...) Let's add "clearly" to our explanation; it was such a stupid mistake that I should have realized it.

It can be seen that Gerald grasped Sheila's confident explanation easily. His comments indicate that he understood Sheila's argument and was not simply echoing her, and was willing to admit his mistake. 
TABLE XIII. Students' categorized explanations regarding the heat in a cyclic process. $N=65$. A typical example from each category is presented after the category symbol in italics.

\begin{tabular}{|c|c|c|c|c|}
\hline \multirow[b]{2}{*}{ Students' explanations } & \multicolumn{4}{|c|}{ Intervention phase } \\
\hline & $\begin{array}{l}\text { Individual } \\
\text { working }\end{array}$ & $\begin{array}{l}p V \text { diagram } \\
\text { hint }\end{array}$ & $\begin{array}{l}\text { Content } \\
\text { hints }\end{array}$ & $\begin{array}{l}\text { Peer } \\
\text { interaction }\end{array}$ \\
\hline $\begin{array}{l}\text { 7A. Because work done by gas is negative, the heat transferred into } \\
\text { the gas must be negative in a cyclic process (correct choice C) }\end{array}$ & $15 \%$ & $20 \%$ & $22 \%$ & $40 \%$ \\
\hline Because $\Delta E_{t h}=0, W=-Q "$ & & & & \\
\hline $\begin{array}{l}\text { 7B. No temperature change/same initial and final states } \\
\text { "The initial and final temperatures are equal" }\end{array}$ & $32 \%$ & $34 \%$ & $34 \%$ & $40 \%$ \\
\hline $\begin{array}{l}\text { 7C. Heat transfer into the gas and away from the gas is equal } \\
\text { "Same amount of heat is transferred into the system and away from it" }\end{array}$ & $11 \%$ & $11 \%$ & $11 \%$ & $6 \%$ \\
\hline $\begin{array}{l}\text { 7D. The whole process is not observed } \\
\text { "At the start, heat was transferred into the gas", }\end{array}$ & $5 \%$ & $5 \%$ & $5 \%$ & $2 \%$ \\
\hline $\begin{array}{l}\text { 7E. Direction of heat transfer is misunderstood } \\
\text { " } W-Q=0, W>0, Q>0 "\end{array}$ & $2 \%$ & $2 \%$ & $2 \%$ & $3 \%$ \\
\hline $\begin{array}{l}\text { 7F. Other or none } \\
\text { "Greater than zero because weights were added on piston at phase 3" }\end{array}$ & $35 \%$ & $29 \%$ & $28 \%$ & $9 \%$ \\
\hline
\end{tabular}

\section{Heat in a cyclic process}

Table XIII shows how effective the intervention can be in increasing the number of correct explanations in the context of heat in a cyclic process. The $p V$ diagram and content hints provided only a little help, but the percentage of correct explanations was almost doubled as a result of the peer discussions. Nevertheless, the common misconception regarding the process nature of heat in category $\mathrm{B}$ was not overcome during the intervention.

The percentages of students' correct multiple-choice selections during the intervention changed as follows: $20 \%$, $26 \%, 25 \%$, and $37 \%$. Of these students, $62 \%, 71 \%, 69 \%$, and $96 \%$ provided accurate explanations during the intervention. Explanations provided by other students making a correct selection were either absent of categorized in 7C.

With regard to the pair discussions, it would seem that they were very useful in this particular task. An example follows.

Chip How about question seven? (...) I don't know for sure; I answered that it is equal [to zero] because it returns to the same [state], but when I think it again.

Dale Well, $\Delta E_{t h}$ is the same [zero] when the initial and final states are the same. And then $W$ has to be equal to $Q$ but opposite in sign.

Chip Oh, yeah.

Dale Well, I'm not sure about this. I have put it the other way round in my first paper, so it would be the remainder of work and heat, not the sum.

Chip Well, I don't think it matters if the sum is negative or whatsoever.

Dale Well, I've thought about heat transfer in a different way from this. In the official version (...) I would claim that the absolute value equals $W$, and the answer is $A$.
Here one can see that Dale was right in his explanation, while Chip, who was more uncertain, was willing to accept this. The problem is, however, that Dale interpreted the first law equation erroneously, and in the end the pair ended up with the wrong answer. Nevertheless, Dale's notion of opposite signs for heat and work in a cyclic process was accurate.

\section{Summary of the intervention's results}

The statistical significance of the intervention phases was evaluated with the aid of McNemar's test. In all of the tasks, explanations in the first category A were considered to be correct, while all of the others were categorized as incorrect. Subsequently, the $X^{2}$ values were calculated with the aid of a number of responses being changed from correct to incorrect $(x)$ and from incorrect to correct $(y)$. The following example is from task 3 , where two students changed their correct explanations to incorrect ones and 19 students did the opposite during the whole intervention:

$$
X^{2}=\frac{(x-y)^{2}}{x+y}=\frac{(2-19)^{2}}{2+19}=13.8 .
$$

With the aid of Microsoft Excel software, the $p$ values were calculated based on $X^{2}$ values and the number of degrees of freedom ( 1 for McNemar's test). In this example, $X^{2}=13.8$ corresponds to the $p$ value 0.0002 , so the change is statistically significant.

The impact of the $p V$ diagram hint was statistically significant in task $6(p=0.03)$, which it was designed for, but other changes were not statistically significant (with a limit of $p=0.05$ ). The second phase, containing the content hints, caused significant growth in task 3 $(p=0.03)$. but other changes were negligible. When these two phases were treated as one, the impact was statistically 
significant in the case of tasks $3(p=0.02), 4(p=0.05)$, and $6(p=0.005)$.

With respect to the peer-interaction phase, the increase in the number of correct explanations varied between $20 \%$ and $85 \%$, with only one exception; the number of correct explanations decreased by $31 \%$ in task 4 , which addresses heat in an isothermal process. The impact of the peer-interaction phase was statistically significant $(0.0001<p<0.02)$ in all but task 5 , with a negative impact on task $4(p=0.03)$.

When the whole intervention is examined as a single entity, the statistical difference was significant $(0.00002<$ $p<0.02$ ) in all but tasks 4 and 5. One should notice that the reduction in the case of task 4 was not statistically significant. Hence, we conclude that the statistics support the findings presented in a more descriptive form above.

\section{Course exam}

In order to probe the permanence of the intervention's impact on students' conceptions, the same themes were addressed in the course exam two weeks after the intervention. We reversed the direction of the original cyclic process and formulated a new set of tasks concerned with the same themes so that every question presented in the original test [17] had a counterpart in the course exam (see Appendix D). As a consequence, we were able to use the same categorization, which would therefore help to show whether the impact of the intervention had endured until at least the course exam. After categorizing students' explanations in the course exam, we evaluated the situation to discover whether the percentages of students in the categories had changed between the intervention and the course exam. In Fig. 1, a comparison of the percentages

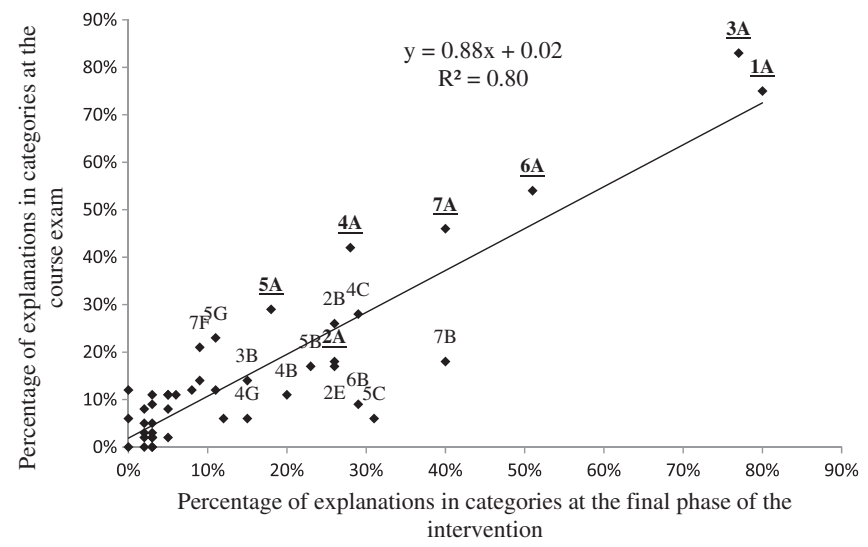

FIG. 1. The percentages of the students' categorized responses in the course exam versus the final phase of the intervention, $N=65$. Data points supplemented with numbers 1-7 and A-E refer to the question numbers and conception categories presented in Tables VII-XIII. The category symbols have been excluded from categories in the case of percentages below $15 \%$ in order to enhance the readability of the figure. The categories $(1 \mathrm{~A}-7 \mathrm{~A})$ referring to correct conceptions are presented in boldface and underlined. of students' categorized responses in the final phase of the intervention and the course exam is presented in a scatter plot with a regression line. For example, students' percentages in the final phase of the intervention and course exam in category $6 \mathrm{~A}$ were $51 \%$ and $54 \%$, respectively. Hence, a data point referring to this category has been placed at their intersection. This was made for all categories. The exact percentages category by category can be found in the Supplemental Material [35].

That the slope of the linear regression line is close to 1 suggests that the percentages of the students' conceptions are relatively equivalent in the final phase of the intervention and in the course exam. The constant term is small compared with the sample size and hence its effect can be ignored. When the $R$-squared value is close to 1 , we can conclude that the deviation is minor. Moreover, the statistical significance of the changes between the final phase of the intervention and the course exam was evaluated with the aid of McNemar's test, using a similar procedure to that described in the preceding section. We observed that the $p$ values varied between 0.06 and 0.65 , which means that there was no statistical difference (within a limit of $p=0.05$ ) between the final phase of the intervention and the course exam.

On the basis of these findings, we would suggest that the impact of the intervention was not temporary in nature, but that it could also be seen in the course exam. The correlation between the responses indicates that the students' ideas remained relatively stable between the intervention and the course exam, despite the impact of self-study that normally precedes a course exam; in fact, the slight increase in the number of correct responses indicates that the effect of self-study was relatively low.

\section{DISCUSSION}

Problems in learning in large lecture courses are well known and widely reported [6,25,36,37]. For the majority of students, lecture-based instruction combined with problem-solving tasks frequently results in only poor conceptual understanding, and yet it still seems to be the dominant teaching method in higher education [37].

Our idea for boosting learning in the course of lectures was to formulate an intervention based on scaffolding in the form of hinting and peer interaction [28-31]. This theoretical base was combined with a diagnostic test addressing the essential thermal physics content [17]. This test was appropriate for the intervention because mastering the test requires not only familiarity with the essential physics content but also concurrently understanding the physical situations and using several principles. As a whole, the intervention aimed at helping students to connect the several pieces of knowledge to one structured entity. Arguably, this kind of knowledge structure can help students to achieve a more permanent understanding [38].

With respect to the results, pretesting revealed that a university lecturer cannot base his or her teaching on the 
assumption that students have grasped the content taught during an earlier phase of their education. The concepts and processes related to the first law of thermodynamics demonstrably had not been understood from students' previous studies; this is a finding that is familiar from previous research $[6,14,16,17]$. For example, confusing the concepts of heat and internal energy is a finding reported previously, as are students' problems with work in the context of thermodynamics [16]. In addition, problems concerning the use of $p V$ diagrams were observed to be prevalent among our students [17]. Surprisingly, however, a widely reported confusion between heat and temperature $[5,6,14,15]$ was almost completely absent as far as our students were concerned. It is likely that this regularly reported misconception had, in their case, already been overcome in the course of their earlier studies.

After receiving conventional teaching at the start of the intervention, the students still possessed a variety of misconceptions. For instance, problems were observed with the process quantities of heat and work $[3,6,16,17,19,20]$, use of the first law of thermodynamics [17], microscopic models $[7,13]$, and thermal processes $[6,13,16]$.

The intervention proved to be effective in terms of increasing the number of correct explanations and multiple-choice selections produced by the students and also reducing the number of misconceptions that they held. If the results of the diagnostic test are compared with the results obtained in previous studies [17,26], it may be noted that the proportion of correct explanations at the end of our intervention and course exam is larger than that reported in post-tests reported in previous studies, the difference being between 15 and 20 percentage points. ${ }^{7}$ The biggest difference can be seen in tasks 6 and 7 addressing work and heat in a cyclic process. Compared with proportions ranging between $10 \%$ and $15 \%$ reported earlier, students in our intervention and course exam scored $40 \%-54 \%$ $[17,26]$. Typically, the proportions of the common misconceptions after our intervention and in the course exam were, with a few exceptions, 10-30 percentage points smaller than in previously published studies: the difference in tasks 2 and 4 addressing work in the isobaric process and heat in the isothermal process was nonexistent or slightly negative $[17,26]$. However, comparisons between universities in different countries have to be regarded with a healthy level of skepticism because of their different educational systems, student populations, and teaching aims.

The relative stability in the number of some misconceptions does not mean that they were not overcome at all. 65\% of the students whose explanations changed during the

\footnotetext{
${ }^{7}$ Meltzer [17] does not give exact figures for correct explanations in every task and hence we approximated, probably optimistically, those to equal numbers of correct multiple choices. Regarding question 5, we utilized looser criteria for this comparison so that it would be more readily comparable to the previous study [26]
}

intervention to being correct had been previously categorized in some other category, and only $18 \%$ of the students did not change their inaccurate explanations at all during the intervention. The stability of such a status in some misconception categories can be explained by the fact that a number of students changed their answers from "other or none" categories to ones containing some misconception. This suggests that learning can take place via misconceptions, or intermediate conceptions. It also means that acquiring a scientific conception may very well require these kinds of "stepping stones," which are not satisfactory per se but may still be helpful along the learning pathway $[39,40]$. However, the role and need for these stepping stones would each require its own research and so we cannot present a more detailed description of them in the course of this article.

With regard to our student sample, we would claim that it represented a typical introductory course cohort in Finland. Because of the differences in other educational systems, generalizations for other countries and systems should be made with caution, especially with regard to students' preknowledge, since the differences in students' earlier studies can be relatively significant. The pretest results indicated that our students possessed conceptions similar to those observed previously $[6,13]$. Moreover, their conceptions after conventional introductory level university teaching are well in line with earlier findings $[6,16,17]$. This suggests that the intervention would probably have a similar impact at other universities. In addition, this intervention is designed so that the lecturer's role in the intervention is minimal, and hence a lecturer's personality would be unlikely to have any impact on the outcome. This claim is reinforced by the fact that the intervention had also been implemented by a different person in a previous study, with similar results [27].

At the same time, we acknowledge the limitations of our study. The sample size $(N=65)$ was relatively modest and so the statistical assessment needs to be interpreted with caution. Nevertheless, the evidence is not based solely on statistical results, but their role has been to support the more descriptive data. As far as the audio recordings are concerned, the small number $(n=5)$ of recorded pairs limits the degree of variety in the discussions being analyzed. Nevertheless, these recordings offered valuable information concerning the impact of the pair discussions on the learning outcome.

As the results indicate, the intervention phases seemed to work well. It would, however, be interesting to see the impact of an intervention if peer discussions preceded the hinting phase. Resequencing the activity in this way might activate students better at the beginning of the intervention. In addition, peer discussion helps its participants to evaluate their own thinking [25], which is essential when mirroring conceptions in relation to the content presented in the hints. We are also considering whether students' wellknown misconceptions could be addressed explicitly in the 
intervention. Currently, they form a base for the hints, but it is possible that this could be enhanced. We doubt whether simply introducing the misconceptions would have an impact, since students need to participate actively in comparing their conceptions with well-known misconceptions. At present, we are considering whether the pair discussion could be replaced by discussions involving three or four persons, since that might awaken even more fruitful and useful discussions [41]. The problem is that a lecture hall poses practical challenges for larger discussions, and hence we decided, rather, to implement pair discussions.

We are also considering constructing similar interventions for other topics that have been shown to be difficult. A similar approach could also be expanded to cover an entire course. This could be carried out by conducting this type of intervention several times during a particular course. For example, in the context of thermal physics similar interventions could be implemented after covering thermal processes and the first law of thermodynamics, the second law of thermodynamics, and the heat engines. This would help students to reorganize their knowledge during the course itself and also to detect potential misconceptions that they may possess. Transparency in terms of our openly introduced subaims would emphasize the most essential topics that students do not necessarily discern during conventional teaching through lectures and problem-solving tasks.

Thus, we would encourage lecturers to use this HPIL teaching in other areas of physics. This method is efficient and relatively straightforward to use: an awareness of students' common misconceptions, suitable hints for addressing them, and proper teaching and testing materials would be sufficient for trying out this approach in large lecture courses. For a lecturer this intervention may constitute the first approachable step towards other research-based instructional approaches that would possibly require larger changes to be made to conventional teaching. The same applies to the students, especially if they are solely used to conventional lecture-based teaching. In summary, this type of intervention may be easier to accept as part of the instruction than some other instructional approaches that might require greater changes to the curriculum.

The greatest challenge is to find teaching materials that can address students' misconceptions effectively. Fortunately, familiarizing oneself with physics education research can offer a lecturer good ideas about the materials that can be helpful in the quest for better learning outcomes.

\section{APPENDIX A: HINTS OFFERED TO STUDENTS}

See Table XIV for hints offered to students.

\section{APPENDIX B: PRETESTING TASKS}

(1) Answer briefly what you think the following concepts mean and describe:

Heat

Work

Internal energy

(2)

(a) Draw $p V$ diagrams for experimenting with gas in (i) isochoric, (ii) isobaric, and (iii) isothermal thermodynamic processes. Using an arrow, label the process direction in which heat is transferred to the gas. Explain your reasoning.

(b) A cyclic process means a process where a thermodynamic system returns to its initial state after two or more changes of state. How would you connect the isochoric, isobaric, and isothermal processes (order and direction) in order to maximize the work done on the gas? A process should include or intersect states 1 and 2. Draw a cyclic process on the adjacent $p V$ diagram (Fig. 2).

(modified from the Finnish Matriculation Examination, Fall 2011 [33])

TABLE XIV. Hints offered to students. The hints are in chronological order.

\begin{tabular}{ll}
\hline \hline Hint & Problem(s) to overcome \\
\hline $\begin{array}{l}\text { A. Present three phases of the process on a } p V \text { diagram } \\
B . \text { The thermal energy of a system may change if a system and }\end{array}$ & Work and heat during a cyclic process \\
$\begin{array}{l}\text { an environment exchange energy as heat } Q \text { or work } \\
W\end{array} E_{\text {th }}=Q+W$ & Problems in applying the first law \\
$\begin{array}{l}\text { Heat } Q \text { is the energy transferred between a system and } \\
\text { the environment due to a temperature difference. }\end{array}$ & Heat as energy in transit \\
$\begin{array}{l}\text { Work } W \text { is the energy transferred between a system and } \\
\text { an environment due to a mechanical interaction. }\end{array}$ & Work as an energy transfer mechanism \\
$\begin{array}{l}\text { Thermal energy of the monatomic gas is directly proportional } \\
\text { to temperature } E_{t h}=\frac{3}{2} n R T\end{array}$ & A problem with the relation between temperature \\
$\begin{array}{l}\text { The temperature of a gas describes the average kinetic energy } \\
\text { of the molecules } e_{\mathrm{avg}}=\frac{1}{2} m\left(v_{\text {rms }}\right)^{2}=\frac{3}{2} k_{b} T\end{array}$ & and thermal energy \\
\hline \hline
\end{tabular}




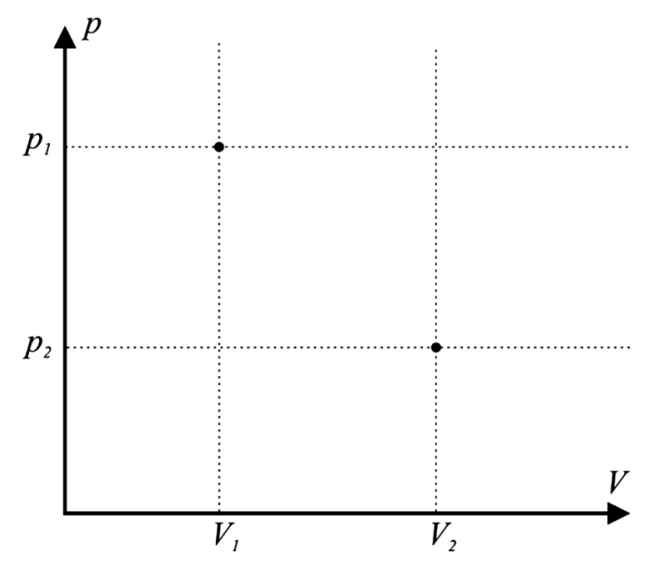

FIG. 2. A $p V$ diagram for the pre-testing task $\mathrm{b}$.

\section{APPENDIX C: INTERVENTION TEST (MODIFIED FROM MELTZER [17])}

Work on the separate answer sheets by choosing the correct multiple-choice alternative and by explaining your choice carefully. Remember to write your name on all of the answer sheets.

A fixed quantity of ideal gas is contained within a metal cylinder that is sealed with a movable, frictionless, insulating piston. The piston can move up or down without the slightest resistance from friction, but no gas can enter or leave the cylinder. The piston is heavy, but there can be no heat transfer to or from the piston itself! The cylinder is surrounded by a large container of water with high walls as shown (Fig. 3).

At initial time $A$, the gas, cylinder, and water have all been sitting in a room for a long period of time, and all of them are at room temperature.

Step 1. We now begin Process \#1: The water container is gradually heated, and the piston very slowly moves upward. At time $B$ the heating of the water stops, and the

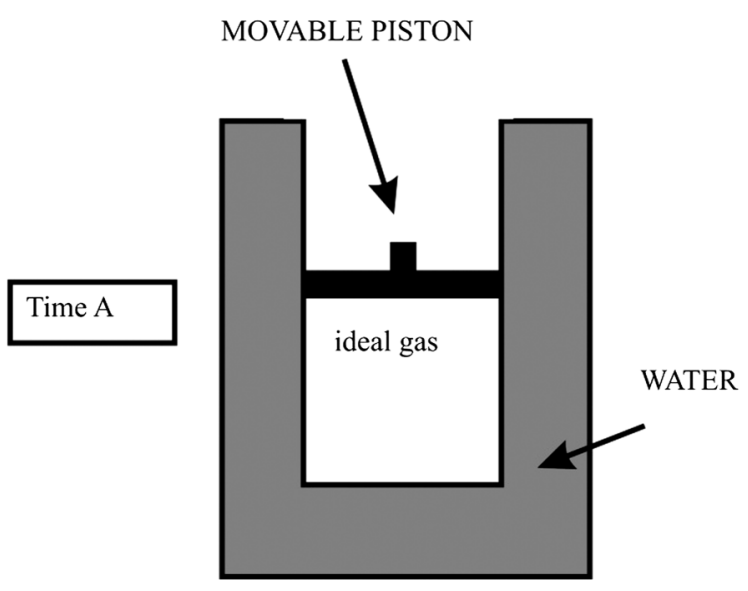

FIG. 3. Ideal gas in a sealed metal cylinder surrounded by a water container.

\section{Time B \\ Piston in new position \\ Temperature of system \\ has changed.}

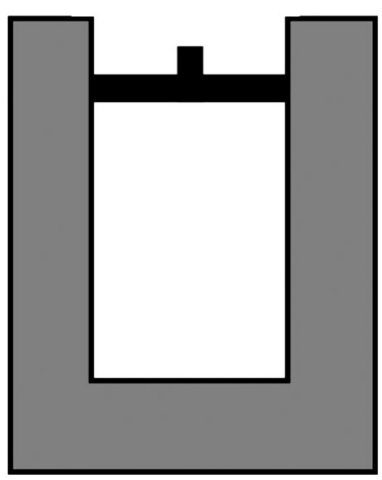

FIG. 4. The ideal gas system at time B.

piston stops moving when it is in the position shown in the diagram below (Fig. 4):

Question \#1: During the process that occurs from time $A$ to time $B$, which of the following is true

(a) positive work is done on the gas by the environment,

(b) positive work is done by the gas on the environment,

(c) no net work is done on or by the gas.

Question \#2: During the process that occurs from time $A$ to time $B$, the gas absorbs $x$ Joules of energy from the water. Which of the following is true: The total kinetic energy of all of the gas molecules

(a) increases by more than $x$ Joules

(b) increases by $x$ Joules

(c) increases, but by less than $x$ Joules

(d) remains unchanged

(e) decreases by less than $x$ Joules

(f) decreases by $x$ Joules

(g) decreases by more than $x$ Joules.

Step 2. Now, empty containers are placed on top of the piston as shown (Fig. 5). Small lead weights are gradually placed in the containers, one by one, and the piston is

Weights being added Piston moves down slowly.

Temperature remains same as at time B.

Lead weights

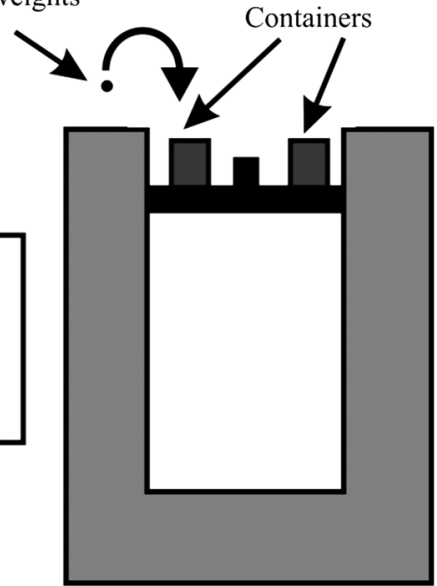

FIG. 5. The ideal gas system at the beginning of the process from time $\mathrm{B}$ to time $\mathrm{C}$. 
Time $\mathrm{C}$

Weight in containers

Piston in same position

as at time $\mathrm{A}$

Temperature same as at

time B

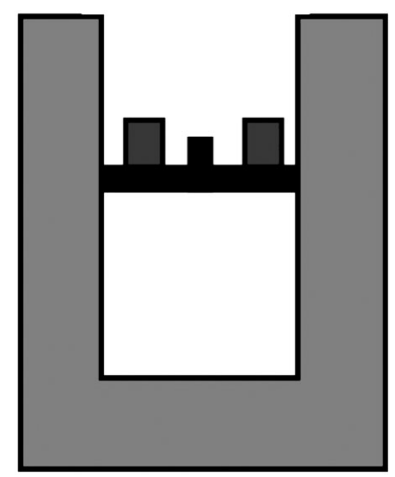

FIG. 6. The ideal gas system at time C.

observed to move down slowly. While this happens, the temperature of the water is nearly unchanged, and the gas temperature remains practically constant. (That is, it remains at the temperature it reached at time $B$, after the water had been heated up.)

Step 3. At time $C$ we stop adding lead weights to the container and the piston stops moving. The piston is now found to be at exactly the same position it was at time A (Fig. 6).

Question \#3: During the process that occurs from time $B$ to time $C$, does the total kinetic energy of all the gas molecules

(a) increase

(b) decrease

(c) remain unchanged?

Question \#4: During the process that occurs from time $B$ to time $C$, is there any net energy flow between the gas and the water?

(a) If no, explain why not.

(b) If yes, is there a net flow of energy from gas to water, or from water to gas?

Step 4. Now, the piston is locked into place so it cannot move; the weights are removed from the piston. The system is left to sit in the room for many hours, and eventually the entire system cools back down to the same room temperature it had at time $A$. When this finally happens, it is time $D$ (Fig. 7).

Time D

Piston is same position as at time A.

Temperature same as at time A.

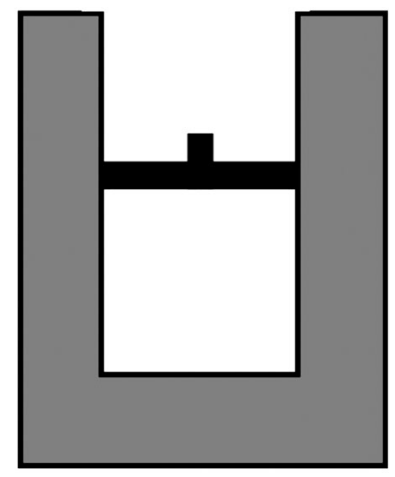

FIG. 7. The ideal gas system at time D.
Question \#5: During the process that occurs from time $C$ to time $D$, the water absorbs $y$ Joules of energy from the gas. Which of the following is true? The total kinetic energy of all of the gas molecules

(a) increases by more than $y$ Joules

(b) increases by $y$ Joules

(c) increases, but by less than $y$ Joules

(d) remains unchanged

(e) decreases, by less than $y$ Joules

(f) decreases by $y$ Joules

(g) decreases by more than $y$ Joules.

Question \#6: Consider the entire process from time $A$ to time $D$. Is the net work done on the gas by the environment during that process

(a) greater than zero

(b) equal to zero

(c) less than zero?

Question \#7: Is the total heat transfer to the gas during that process
(a) greater than zero
(b) equal to zero
(c) less than zero?

\section{APPENDIX D: POST-TEST}

Corresponding question numbers from the intervention test (Appendix C) are presented in brackets after the tasks. For example, the first question in this test corresponds to question number 3 in the original intervention test.

Monatomic ideal gas is sealed in a piston-cylinder system. A piston can move without any friction, and it can be locked in its position when needed. Energy transfer can occur between the gas and environment. There are small weights on the top of the piston, so the mass of the piston can be modified.

Answer the following questions related to the three-phase process described below. Remember to explain your answers; you cannot gain full points with oversimplified answers.

Imagine the start of a process from state A to state B. Small weights are removed from the top of the piston, and the piston slowly moves upward. The temperature of the gas does not change during this process. Removing the weights is stopped when the piston's height has been doubled.

(1) What happens to the average kinetic energy of the gas atoms during process $\mathrm{AB}$ ? (3)

(a) The average kinetic energy of the gas atoms increases

(b) The average kinetic energy of the gas atoms decreases

(c) The average kinetic energy of the gas atoms remains the same 
(2) Is there any heat transfer between the gas and its surroundings during process AB? (4)

(a) Yes, from the gas to the environment

(b) No

(c) Yes, from the environment to the gas

Now continue to the next process, from state B to state C. A piston-cylinder system is immersed in an ice-water bath, and the piston moves downward slowly. When the piston reaches the same height as in state A, cooling is stopped and the piston stops. During process BC, water absorbs $x$ joules of heat from the gas.

(3) What can you say about the work done on the gas during process BC? (1)

(a) Work done on the gas is positive

(b) There is no work done

(c) Work done on the gas is negative

(4) What happens to the total kinetic energy of the gas particles during process $\mathrm{BC}$ ? (2)

(a) It increases by more than $x$ joules

(b) It increases by $x$ joules

(c) It increases by less than $x$ joules

(d) It remains unchanged

(e) It decreases by less than $x$ joules

(f) It decreases by $x$ joules

(g) It decreases by more than $x$ joules
Finally, continue to the process from state $\mathrm{C}$ to state $\mathrm{D}$. The piston is locked in its position, the ice-water bath is removed, and the gas slowly reaches its original temperature. Thus, the temperature in state $\mathrm{D}$ is the same as in state $\mathrm{A}$. During process $\mathrm{CD}$, surroundings give out $y$ joules of energy to the gas.

(5) What happens to the total kinetic energy of the gas particles during process $\mathrm{CD}$ ? (5)

(a) It increases by more than $y$ joules

(b) It increases by $y$ joules

(c) It increases by less than $y$ joules

(d) It remains unchanged

(e) It decreases by less than $y$ joules

(f) It decreases by $y$ joules

(g) It decreases by more than $y$ joules

The whole process from $\mathrm{A}$ to $\mathrm{D}$ is examined in questions 6 and 7.

(6) During the whole process from A to D, is the net work done on the gas (6)

(a) Larger than zero?

(b) Equal to zero?

(c) Smaller than zero?

(2) During the whole process from A to D, is the heat transfer to the gas (7)

(a) Larger than zero?

(b) Equal to zero?

(c) Smaller than zero?
[1] H. D. Young and R. A. Freedman, University Physics With Modern Physics (Pearson, San Francisco, 2004), 11th ed.

[2] P. L. Thomas and R. W. Schwenz, College physical chemistry students' conceptions of equilibrium and fundamental thermodynamics, J. Res. Sci. Teach. 35, 1151 (1998).

[3] P.H. van Roon, H.F. van Sprang, and A.H. Verdonk, 'Work' and 'heat': On a road towards thermodynamics, Int. J. Sci. Educ. 16, 131 (1994).

[4] L.C. McDermott and P.S. Shaffer, Tutorials in Introductory Physics (Pearson, Boston, 2010).

[5] J. Barbera and C. E. Wieman, Effect of a dynamic learning tutorial on undergraduate students' understanding of heat and the first law of thermodynamics, Chem. Educ. 14, 45 (2009).

[6] C. H. Kautz, P. R. L. Heron, M.E. Loverude, and L.C. McDermott, Student understanding of the ideal gas law, Part I: A macroscopic perspective, Am. J. Phys. 73, 1055 (2005).

[7] C.H. Kautz, P.R.L. Heron, P.S. Shaffer, and L.C. McDermott, Student understanding of the ideal gas law, Part II: A microscopic perspective, Am. J. Phys., 73, 1064 (2005).

[8] J. Clement, D. E. Brown, and A. Zietsman, Not all preconceptions are misconceptions: Finding 'anchoring conceptions' for grounding instruction on students' intuitions, Int. J. Sci. Educ. 11, 554 (1989).

[9] S. Vosniadou, in Reconsidering Conceptual Change: Issues in Theory and Practice, edited by M. Limon and L. Mason (Kluwer, Dordrecht, 2002), pp. 61-76.

[10] D. Hammer, More than misconceptions: Multiple perspectives on student knowledge and reasoning, and an appropriate role for education research, Am. J. Phys. 64, 1316 (1996).

[11] M.F. Thomaz, I. M. Malaquias, M. C. Valente, and M. J. Antunes, An attempt to overcome alternative conceptions related to heat and temperature, Phys. Educ. 30, 19 (1995).

[12] S. Rozier and L. Viennot, Students' reasonings in thermodynamics, Int. J. Sci. Educ. 13, 159 (1991).

[13] R. Leinonen, E. Räsänen, M. Asikainen, and P.E. Hirvonen, Students' pre-knowledge as a guideline in the teaching of introductory thermal physics at university, Eur. J. Phys. 30, 593 (2009).

[14] H. Beall, Probing student misconceptions in thermodynamics with in-class writing, J. Chem. Educ. 71, 1056 (1994).

[15] S. Kesidou and R. Duit, Students' conceptions of the second law of thermodynamics-An interpretive study, J. Res. Sci. Teach. 30, 85 (1993). 
[16] M. E. Loverude, C. H. Kautz, and P. R. L. Heron, Student understanding of the first law of thermodynamics: Relating work to the adiabatic compression of an ideal gas, Am. J. Phys. 70, 137 (2002).

[17] D. E. Meltzer, Investigation of students' reasoning regarding heat, work, and the first law of thermodynamics in an introductory calculus-based general physics course, Am. J. Phys. 72, 1432 (2004).

[18] C. A. Doige and T. Day, A typology of undergraduate textbook definitions of 'heat' across science disciplines, Int. J. Sci. Educ. 34, 677 (2012).

[19] T. J. Greenbowe and D.E. Meltzer, Student learning of thermochemical concepts in the context of solution calorimetry, Int. J. Sci. Educ. 25, 779 (2003).

[20] G. S. M. Moore, General, restricted and misleading forms of the first law of thermodynamics, Phys. Educ. 28, 228 (1993).

[21] R. Leinonen, M. A. Asikainen, and P.E. Hirvonen, University students explaining adiabatic compression of an ideal gas-A new phenomenon in introductory thermal physics, Res. Sci. Educ. 42, 1165 (2012).

[22] R. D. Knight, Instructor guide. Physics for scientists and engineers-A strategic approach (Pearson, San Francisco, 2008).

[23] R.D. Knight, Physics for scientists and engineers-A strategic approach (Pearson, San Francisco, 2008), 2nd ed.

[24] R. D. Knight, Student workbook. Physics for scientists and engineers-A strategic approach (Pearson, San Francisco, 2008).

[25] C.H. Crouch and E. Mazur, Peer instruction: Ten years of experience and results, Am. J. Phys. 69, 970 (2001).

[26] R. Leinonen, M. A. Asikainen, and P.E. Hirvonen, Proceedings of the International Conference on Physics Education GIREP-ICPE-MPTL, Reims, 2010 (to be published).

[27] R. Leinonen, M.A. Asikainen, and P.E. Hirvonen, in Proceedings of the GIREP-EPEC Conference, Jyväskylä, 2011, edited by A. Lindell, A.-L. Kähkönen, and J. Viiri (University of Jyväskylä, Jyväskylä, 2012), p. 92.

[28] E. A. Davis and N. Miyake, Explorations of scaffolding in complex classroom systems, J. Learn. Sci. 13, 265 (2004).
[29] D. Wood, J. S. Bruner, and G. Ross, The role of tutoring in problem solving, J. Child Psychol. Psychiatry 17, 89 (1976).

[30] T. Greening, Scaffolding for success in problem-based learning, Med. Educ. Online 3, 1 (1998).

[31] X. Ge and S. M. Land, Scaffolding students' problemsolving processes in an ill-structured task using question prompts and peer interactions, Educ. Technol. Res. Dev. 51, 21 (2003).

[32] P. Heller, R. Keith, and S. Anderson, Teaching problem solving through cooperative grouping. Part 1: Group versus individual problem solving, Am. J. Phys. 60, 627 (1992).

[33] E. Arminen and J. Valjakka, Fysiikan ylioppilastehtävät ratkaisuineen (MFKA-kustannus OY, Helsinki, 2012).

[34] S. Elo and H. Kyngäs, The qualitative content analysis process, J. Adv. Nurs. 62, 107 (2008).

[35] See Supplemental Material at http://link.aps.org/ supplemental/10.1103/PhysRevSTPER.9.020112 for exact percentages in the final phase of the intervention and in the course exam.

[36] L. C. McDermott, Millikan Lecture 1990: What we teach and what is learned-Closing the gap, Am. J. Phys. 59, 301 (1991).

[37] C. Henderson and M. H. Dancy, Impact of physics education research on the teaching of introductory quantitative physics in the United States, Phys. Rev. ST Phys. Educ. Res. 5, 020107 (2009).

[38] J. D. Bransford, A. L. Brown, and R. R. Cocking, How People Learn: Brain, Mind, Experience, and School (National Academy Press, Washington, DC, 2000), expanded edition.

[39] P. Juergen and H. Niedderer, A learning pathway in highschool level quantum atomic physics, Int. J. Sci. Educ. 20, 1075 (1998).

[40] H. Niedderer, in Bridging Research Methodology and Research Aims, Student and Faculty Contributions from the 5th ESERA Summer School in Gilleleje, edited by R.H. Evans, A.M. Andersen, and H. Sørensen (The Danish University of Education, Gilleje, 2001), pp. 397-414.

[41] E. Alexopoulou and R. Driver, Small-group discussions in physics-Peer-interaction modes in pairs and fours, J. Res. Sci. Teach. 33, 1099 (1996). 